\title{
Strategic party formation on a circle and Duverger's Law
}

\author{
Ronald Peeters ${ }^{1}$. Rene Saran ${ }^{2}$. \\ Ayşe Müge Yüksel ${ }^{1}$
}

Received: 18 December 2013 / Accepted: 18 August 2016 / Published online: 30 August 2016 (C) The Author(s) 2016. This article is published with open access at Springerlink.com

\begin{abstract}
Duverger's Law states that plurality rule tends to favor a two-party system. We study the game-theoretic foundations of this law in a spatial model of party formation and electoral competition. The standard spatial model assumes a linear agenda space. However, when voters vote sincerely, electoral competition on the line under plurality rule gravitates towards a single party located at the median. We therefore depart from the linear space and instead adopt the unit circle as the space of agendas. We characterize pure-strategy (subgame-perfect) Nash equilibria under both sincere and strategic voting. Under both voting behaviors, multiple configurations of parties are possible in equilibrium. We refine our predictions using a new notion called defection-proof (subgame-perfect) Nash equilibrium. Under sincere voting, either two or three parties are effective in defection-proof Nash equilibria, whereas under strategic voting, either one or two parties are effective in defection-proof subgame-perfect Nash equilibria. These results are partially consistent with Duverger's Law.
\end{abstract}

We thank Aitor Calo Blanco, Eric Maskin, Arno Riedl, Kaj Thomsson and the participants of the 21st Jerusalem School in Economic Theory on Political Economy and MLSE (Maastricht) for useful comments and suggestions.

$凶$ Ronald Peeters

r.peeters@maastrichtuniversity.nl

Rene Saran

rene.saran@yale-nus.edu.sg

Ayşe Müge Yüksel

a.yuksel@maastrichtuniversity.nl

1 Department of Economics, Maastricht University, PO Box 616, 6200 MD Maastricht, The Netherlands

2 Division of Social Sciences, Yale-NUS College, 16 College Ave West \#02-221, Singapore 138527, Singapore 
“Extremism is so easy. You've got your position, and that's it. It doesn't take much thought. And when you go far enough to the right you meet the same idiots coming around from the left."

—Clint Eastwood, Time Magazine, February 20, 2005

\section{Introduction}

In democratic societies, collective decisions are made in legislatures. Legislators are often grouped into parties. Party representation and configuration in turn depend on the political framework (cf. Rae 1971; Lijphart 1990; Taagepera and Shugart 1989) and the particular strategies adopted by politicians, parties and voters within that framework. Duverger's Law states that plurality voting in single member districts tends to favor a two-party system (Duverger 1954; Riker 1982). Theoretical support for this law has been provided in Cox (1987), Palfrey (1989), Feddersen (1992) and Fey (1997) by assuming strategic voters who avoid wasting their vote on "hopeless" candidates and in Rivière (1998) and Osborne and Tourky (2008) by assuming economies of party size. Fey (2007) finds support for the law in a setting with sincere voters and pure policy-motivated candidates when the available policies are the corner points of the unit square. ${ }^{1}$ In this paper, we aim to contribute to the game-theoretic foundation of Duverger's Law.

The theoretical literature on political party formation and configuration typically builds on the Downsian model of electoral competition, which assumes voters to be distributed along a line segment representing the agenda space (Downs 1957a). We believe that the linear model of electoral competition is not suitable for this research as the incentives to attract the median voter easily generate a single party in the pluralistic system under sincere voting when we consider equilibrium refinements that allow movements at the party level (see Sect. 5). This motivates our point of departure from the standard framework: We instead assume that the set of agendas equals the unit circle. We hereby follow in the success of the industrial organization literature in studying multi-firm competition by moving from Hotelling's linear city (Hotelling 1929) to Salop's circular city (Salop 1979). ${ }^{2}$

Before continuing, we believe some justification for using the circle as the agenda space is needed and we provide two views we believe are better captured by the circle than by the line. ${ }^{3}$

First, in political science, the horseshoe theory stipulates that parties usually depicted as far-left and far-right are more similar to each other in essentials than either are to the political center, and hence the political spectrum is better represented by a horseshoe than with a linear bar. ${ }^{4}$ For instance, both extremes typically disapprove of

\footnotetext{
1 Other papers that explain the existence of parties, without particularly focusing on Duverger's prediction, include Osborne and Slivinski (1996), Besley and Coate (1997), Jackson and Moselle (2002), Snyder and Ting (2002), Levy (2004) and Morelli (2004).

2 According to Persson and Tabellini (2000, p. 5), "It is hard to model the outcome of multiparty competition ...". As we will see, the transition to a circular agenda space may be a step forward.

3 The circular agenda space can also arise as a social compromise while drawing a constitution. See the online supplement at https://drive.google.com/open?id=0B8Sv4TBdx30JQ1hocW5qU01OYjQ.

4 This theory is attributed to the French post-postmodernist philosopher Jean-Pierre Faye. See Faye (1973).
} 
immigration: Labor unions because aliens take their jobs and strong nationalists view aliens as a threat to the native culture. They also share a similar distaste for foreign aid: Extreme left because foreign aid usually ends up in the hands of corrupt elites and bolsters pro-market policies and extreme right because it bolsters inefficient public sector. A prime example for a country where the left and right extreme parties can be considered to be competing for the same voters is the Netherlands. Parties that are usually considered extreme right (PVV) and left (SP) both have a nationalistic focus concerning geopolitical issues and plea for increasing investments in public health and security, lowering bureaucracy and taxes for households, small-scale education and cutting budgets for defense and the royal family. According to the Dutch political barometer of 22 October 2015 by Ipsos, $19.3 \%$ of the voters that voted for the SP in the latest elections indicated that they intend to vote for the PVV in the next elections. ${ }^{5}$

Second, even when extreme ideological positions do not coincide, the literature on political psychology tells us that right and left wing extremists (including radicals, reactionists, fundamentalists and fanatics) have similarities in their cognitive styles, the ways of engaging with political opposition, and the means of achieving their goals (cf. McClosky and Chong 1985; Brandt et al. 2015).

The summary description of our model is as follows. There are a finite number of politicians that simultaneously and independently choose to promote agendas in the elections, where the set of agendas is the unit circle. Politicians promoting the same agenda form a party. Hence, the party structure follows directly from the politicians' decisions to promote agendas. We assume that the voters are uniformly distributed over the unit circle, with each voter's most preferred agenda coinciding with her location on the circle. We consider both the situation where voters are assumed to vote sincerely (i.e., support the party closest to their most preferred agendas) and to vote strategically. Next, the pluralitarian electoral system assigns all power to the parties with the highest vote share (winner takes all). We assume that the politicians belonging to a party share equally in its power, and each politician is opportunistic (office-motivated), trying to maximize her individual power. Hence, in general, each politician prefers to become a member of a party with a high vote share but as few other members as possible.

We provide a full characterization of the sets of pure-strategy (subgame-perfect) Nash equilibria in both the case of sincere and strategic voting, and show that these sets are nonempty. Typically, both situations possess a rich set of equilibria. ${ }^{6}$ Therefore, we define notions of defection-proofness to refine the Nash predictions. This refinement is similar in motivation to coalition-proof Nash equilibrium (Bernheim et al. 1987) but only allows for particular deviations, which we call defections. ${ }^{7}$ The defections

\footnotetext{
5 The Ipsos survey is available at http://www.ipsos-nederland.nl/ipsos-politieke-barometer/winst-enverlies.

6 A high multiplicity of (types of) equilibria is also found in a two-stage location-quantity game along the circle's circumference in Gupta et al. (2004).

7 A characterization of the coalition-proof Nash equilibrium (CPNE) under plurality rule is technically challenging as CPNE allows for too many coalitional deviations, some of which we regard implausible (i.e., deviations for which we did not find any empirical support) in the present context. Our notion of defectionproof Nash equilibrium aims to implement the notion of CPNE while restricting coalitional deviations to the plausible ones. We believe the normative appeal of our selection concept may apply to (mis)coordination games in general, but are not sure whether it predicts and selects for all types of (mis)coordination games. The
} 
include deviations by a coalition of politicians that are typically observed in reality; for instance, shifts in agenda, mergers of parties, and a set of politicians splitting from their original parties and forming a new party or joining an existing one. ${ }^{8}$ For the situation with strategic voters, we also consider defections by voters, which involves a coalition of voters agreeing to vote for a specific party.

We show that, in the situation with sincere voting, Nash equilibria that generate strictly more than three parties are not defection-proof. Intuitively, sincere voting creates incentives for parties supporting adjacent agendas to come to a compromise by supporting an agenda that lies in the middle of their original positions. Although such a compromise creates a larger party, this party garners a plurality of the votes whenever there are at least four parties before this coalitional defection. Moreover, this compromise is credible as it ensures that no defecting subcoalition can gain a plurality. We also show that defection-proofness rules out equilibria with exactly one party when voters are sincere. A single party equilibrium is easily undermined by a defection by a single politician since the defecting politician garners exactly half the votes (contrast this with the result on a line where the single party located at the median cannot be undermined by any defection). Thus, our defection-proof Nash equilibrium predictions under sincere voting are only partially consistent with Duverger's Law: We predict either two or three parties to be effective under sincere voting.

In the situation with strategic voting, any configuration of political parties can be supported as a subgame-perfect Nash equilibrium since voters are atomless. When refining these predictions using our notion of defection-proofness that allows any mass of voters to defect, we find that configurations with three or more parties do not survive. Whenever three or more parties are equally likely to gain power, there exists a coalition of voters located around the midpoint between any two parties who would switch their votes to their second most preferred party-which causes that party to win-rather than vote sincerely as these voters prefer that their second most preferred party gains power for sure over a lottery in which parties that are even worse are likely to gain power. We also show that defection-proof equilibria with one or two parties exist when we restrict the defections by voters to groups of less than half of the total electorate. Hence, our defection-proof predictions under strategic voting too are only

\footnotetext{
Footnote 7 continued

set of defection-proof Nash equilibria includes the set of strong Nash equilibria (Aumann 1959). However, a priori, there is no logical relation between CPNE and defection-proof Nash equilibria. A defection-proof Nash equilibrium is immune to self-enforcing or credible defections by any coalition (i.e., defections from which there are no further credible defections by any subcoalition). On the other hand, a CPNE is immune to credible deviations by any coalition (i.e., deviations from which there are no further credible deviations by any subcoalition). The set of possible defections by a coalition is a subset of the set of deviations by that coalition. Nevertheless, the set of credible defections by a coalition is not necessarily a subset or superset of the set of credible deviations.

8 Duverger already reasoned that the field of parties is trimmed to just two by the forces of "fusion" and elimination (cf. Fey 1997). According to Kaminski (2006), "party politics revolves around the emergence of new parties [and] electoral splits and coalitions." In Eguia (2013), the stability of a party configuration or voting bloc in an assembly is defined with respect to immunity of the current configuration against fourteen classes of deviations. Our definition of defections includes twelve of these classes-exception being classes D1 and D3 in which a subset of politicians deviate to become independents or singleton parties. Hence, considering only defections does not seem to be too restrictive.
} 
partially consistent with Duverger's Law: We predict either one or two parties to be effective under strategic voting.

The rest of the paper is organized as follows. We present the model and definitions in Sect. 2. Sections 3 and 4 present the results for sincere and strategic voting, respectively. We compare our results to those of the linear agenda space in Sect. 5. Section 6 summarizes our results. Proofs for sincere and strategic voting are collected in Appendices 7 and 8, respectively.

\section{Model and definitions}

There is a finite set of politicians $I$ with $|I| \geq 3 .{ }^{9}$ The set of agendas $A$ is the circumference of a circle of unit length. An agenda is denoted by $a$. Voters are uniformly distributed on $A .{ }^{10}$ We identity each voter by her location on $A$.

There are two stages in our model:

Stage I: The I politicians simultaneously choose to support agendas on the circle. We restrict attention to pure strategies. Therefore, $A$ is the set of strategies for each politician. The politicians' strategy profile is denoted by $s$. For any $J \subseteq I, s_{J}$ denotes the strategy profile $\left(s_{i}\right)_{i \in J}$ and $s_{-J}$ denotes the strategy profile $\left(s_{i}\right)_{i \in I \backslash J}$.

The politicians' strategy profile $s$ defines a partition $\mathcal{P}(s)$ of the set of politicians, where each $P \in \mathcal{P}(s)$ is such that for some agenda $a, s_{i}=a$ for all $i \in P$ and $s_{j} \neq a$ for all $j \notin P$. That is, every politician who belongs to $P$ supports the same agenda $a$ in the profile $s$ and none of the politicians outside $P$ support the agenda $a$. We will refer to any $P \in \mathcal{P}(s)$ as a party. Hence, $\mathcal{P}(s)$ is the set of all parties formed under the politicians' strategy profile $s$. The agenda supported by a party $P \in \mathcal{P}(s)$ is the unique agenda supported by every politician who belongs to $P$.

Stage II: Let $s$ be the politicians' strategy profile in Stage I and $\mathcal{P}(s)$ be the resulting set of political parties formed under $s$. In Stage II, each voter casts her vote for one of the parties in $\mathcal{P}(s)$. We assume that all voters play pure strategies. Hence, the voters' strategy profile is a mapping $v_{s}: A \rightarrow \mathcal{P}(s)$ such that the voter located at agenda $a$ votes for the political party $v_{s}(a)$. We restrict attention to strategy profiles $v_{s}$ that are Lebesgue measurable.

Given $s$ in Stage I and $v_{s}$ in Stage II, the weight $w_{P}\left(s, v_{s}\right)$ of a party $P \in \mathcal{P}(s)$ is the measure of voters who vote for party $P$ under the voters' strategy profile $v_{s}$. Note that $w_{P}\left(s, v_{s}\right) \geq 0$ for all $P \in \mathcal{P}(s)$ and $\sum_{P \in \mathcal{P}(s)} w_{P}\left(s, v_{s}\right)=1$. Thus, $w\left(s, v_{s}\right)=\left(w_{P}\left(s, v_{s}\right)\right)_{P \in \mathcal{P}(s)}$ is the resulting distribution of weights over parties in $\mathcal{P}(s)$.

\footnotetext{
$9|X|$ is the cardinality of set $X$.

10 We can easily relax this assumption and allow for a wider set of distributions of the voters over the circle: As long as any interval on the circle can be split in two such that the mass on this interval is equally divided, we obtain qualitatively similar results. Likewise, our results generalize to any agenda space that is homeomorphic to a circle over which voters are uniformly distributed.
} 
A voting rule $\rho$ defines for each strategy profile $\left(s, v_{s}\right)$ the power $\rho_{P}\left(w\left(s, v_{s}\right)\right)$ of each party $P \in \mathcal{P}(s)$ as a function of the distribution of weights $w\left(s, v_{s}\right)$. In this paper, we restrict attention to the plurality rule ${ }^{11}$ so that all parties with the maximum weight share power equally whereas any party with less than the maximum weight gets zero power. Formally, for any $\left(s, v_{s}\right)$, the plurality rule defines the power of any $P \in \mathcal{P}(s)$ as

$$
\rho_{P}\left(w\left(s, v_{s}\right)\right) \equiv \begin{cases}\frac{1}{\left|\arg \max _{P^{\prime} \in \mathcal{P}(s)} w_{P^{\prime}}\left(s, v_{s}\right)\right|}, & \text { if } P \in \arg \max _{P^{\prime} \in \mathcal{P}(s)} w_{P^{\prime}}\left(s, v_{s}\right) \\ 0, & \text { otherwise. }\end{cases}
$$

For any strategy profile $\left(s, v_{s}\right)$, we say that a party $P \in \mathcal{P}(s)$ is effective under $v_{s}$ if it has positive power, i.e., $\rho_{P}\left(w\left(s, v_{s}\right)\right)>0$.

We assume that the politicians belonging to a party share equally in its power. Furthermore, politicians receive utility equal to their individual power - such officemotivated politicians are standard in the literature (cf. Downs 1957b). Hence, the utility of politician $i$ under the strategy profile $\left(s, v_{s}\right)$ is $u_{i}\left(s, v_{s}\right)=\frac{\rho_{P}\left(w\left(s, v_{s}\right)\right)}{|P|}$, where $i \in P \in \mathcal{P}(s) .^{12}$

Let $u\left(a^{\prime} ; a\right)$ denote the utility of the voter located at $a$ when there is a single effective party that supports agenda $a^{\prime}$. We assume that $u$ is a continuous function in both arguments and $u\left(a^{\prime} ; a\right)<u\left(a^{\prime \prime} ; a\right)$ if and only if $a^{\prime}$ is located at areater distance from $a$ than $a^{\prime \prime} .{ }^{13}$ Thus, each voter's location on $A$ is her most-preferred agenda and her utility decreases continuously in the distance between her most-preferred agenda and the agenda supported by the single effective party. If two or more parties are effective, then we assume that the voters consider each agenda supported by these effective parties as equally likely and evaluate the resulting lottery over agendas by its expected utility.

In subsequent sections, we will analyze "defection-proof" equilibria both under sincere and strategic voting. Although the notion of equilibrium (Nash or subgame-perfect Nash) differs based on the voters' behavior (therefore, we leave these definitions until the relevant sections), we can give general definitions for defections and credible defections that can be applied to both sincere and strategic voting models. Our definition of defection allows for the possibility of coordinated deviation by a coalition of players (either politicians or voters but not both).

To define defection and credible defection by politicians, suppose the voters' behavior in Stage II is given by $\left(v_{\tilde{s}}\right)_{\tilde{s} \in A^{|I|}}$, i.e., voters vote according to the strategy profile $v_{\tilde{s}}$ in Stage II following each $\tilde{s} \in A^{|I|}$ in Stage I.

Definition 1 (Defection by politicians) Given $\left(v_{\tilde{s}}\right)_{\tilde{s} \in A^{|I|}}$, a defection from the politicians' strategy profile $s$ by a coalition $J \subseteq I$ is a strategy profile for coalition $J$,

\footnotetext{
11 See the working paper version (Peeters et al. 2010) for the proportional rule.

12 Equivalently, we can assume that (a) parties with maximum weight are equally likely to win the election, (b) the party that ex-post wins the election obtains power of 1 which is shared equally by its members, and (c) the politicians maximize their expected utilities.

13 The distance between two agendas is the length of the smaller arc between them.
} 
$s_{J}^{\prime} \in A^{|J|}$, such that $s_{j} \neq s_{j}^{\prime}=a$ for all $j \in J$, and $u_{j}\left(\left(s_{J}^{\prime}, s_{-J}\right), v_{\left(s_{J}^{\prime}, s_{-J}\right)}\right)>$ $u_{j}\left(\left(s_{J}, s_{-J}\right), v_{\left(s_{J}, s_{-J}\right)}\right)$ for all $j \in J .^{14}$

Thus, a defection by politicians is a deviation from the politicians' strategy profile by a coalition of politicians that satisfies two requirements: First, all the members of the coalition deviate to the same agenda, and second, all the members of the coalition must strictly improve their utilities after the deviation. The following are some examples of defections by politicians:

- Shift in a party's agenda: All the politicians in a party decide to shift the agenda supported by their party.

- Split in a party: A subset of politicians belonging to a party form a new party by supporting a different agenda.

- Merger of parties: All the politicians in two or more parties choose to support a new common agenda.

- A set of politicians split from their original parties and merge at a new or some previously supported agenda.

Such defections by politicians are quite common in politics, and therefore we allow for them in our model. However, unless binding agreements are possible among the defecting coalition, the defection must be self-enforcing or credible.

Definition 2 (Credible defection by politicians) Given Stage II strategies $\left(v_{\tilde{s}}\right)_{\tilde{s} \in A^{|I|}}$ :

(i) A credible defection from the politicians' strategy profile $s$ by a politician $j \in I$ is a $s_{j}^{\prime} \in A$ such that $s_{j}^{\prime}$ is a defection from $s$ by politician $j$.

(ii) A credible defection from the politicians' strategy profile $s$ by a coalition $J \subseteq I$ such that $|J|>1$ is a strategy profile for coalition $J, s_{J}^{\prime} \in A^{|J|}$, such that $s_{J}^{\prime}$ is a defection from $s$ by coalition $J$ and there does not exist any subcoalition $J^{\prime} \subset J$ with a credible defection from $\left(s_{J}^{\prime}, s_{-J}\right)$.

Thus, a credible defection by a coalition of politicians is such that no further credible defection is possible by any proper subcoalition of politicians. ${ }^{15}$ We similarly define defection and credible defection by voters.

\footnotetext{
14 It is standard to assume that while contemplating a deviation, a coalition considers the strategy of the complement as fixed. One could imagine a stronger notion of defection which requires that in case the defecting coalition of politicians chooses an agenda that is already supported by another party, then the politicians in the latter party should also be better-off. The resulting notion of defection-proofness can easily be shown to make precisely the same selection among (a) Nash equilibria under sincere voting as in Theorem 3 and (b) subgame-perfect Nash equilibria under strategic voting as in Theorems 5 and 6. However, this stronger definition of defection by politicians is not consistent with Nash equilibrium. After all, in Nash equilibrium, we consider defections by single politicians but do not care in case such a defection makes the party that this single politician joins worse-off. Therefore, we should stick with the current weaker notion of defection by politicians.

15 In case the defecting coalition joins another party, we might be interested in the stability of the resulting party rather than that of the defecting coalition. For instance, suppose the coalition of politicians $\{1,2,3\}$ defects to join the party comprising of politicians $\{4,5,6\}$. Now, even though no proper subcoalition of the original defectors $\{1,2,3\}$ has a further credible defection, we might want to seriously consider the possibility that some other coalition in the new party $\{1,2,3,4,5,6\}$, which does not include all of the original defectors $\{1,2,3\}$, has a credible defection. However, this possibility does not arise in our model as
} 
Definition 3 (Defection by voters) Consider Stage II following the politicians' strategy profile $s$.

(i) Let $B \subseteq A$ be a subset of voters with a positive measure. A defection from $v_{s}$ by $B$ is a voters' strategy profile $v_{s}^{\prime}$ such that $v_{s}(a)=v_{s}^{\prime}(a)$ for all $a \notin B$, $v_{s}(a) \neq v_{s}^{\prime}(a)=P \in \mathcal{P}(s)$ for all $a \in B$, and every voter in $B$ gets greater utility under $v_{s}^{\prime}$ than under $v_{s}$.

(ii) Pick any $\delta$ such that $0<\delta \leq 1$. A $\delta$-defection from $v_{s}$ is a defection from $v_{s}$ by a subset of voters $B$ that has at most $\delta$ measure.

Thus, a defection by voters is a deviation from the voters' strategy profile by a coalition of voters that has a positive measure ${ }^{16}$ which satisfies two requirements: First, all the members of the coalition deviate to vote for the same party, and second, all the members of the coalition must strictly improve their utilities after the deviation. The notion of $\delta$-defection by voters restricts attention to those defections by voters in which the size of the defecting coalition of voters is bounded by $\delta$.

Definition 4 (Credible defection by voters) Consider Stage II following the politicians' strategy profile $s$.

(i) Let $B \subseteq A$ be a subset of voters with a positive measure. A credible defection from $v_{s}$ by $B$ is a voters' strategy profile $v_{s}^{\prime}$ such that $v_{s}^{\prime}$ is a defection from $v_{s}$ by $B$ and there does not exist a subset of voters $C \subset B$ such that $C$ has a positive but smaller measure than $B$ and there is a credible defection from $v_{s}^{\prime}$ by $C{ }^{17}$

(ii) A credible $\delta$-defection from $v_{s}$ is a credible defection from $v_{s}$ by a subset of voters $B$ that has at most $\delta$ measure.

Thus, a credible defection by a coalition of voters is such that no further credible defection is possible by any proper subcoalition of voters. The notion of credible $\delta$ defection by voters restricts attention to those credible defections by voters in which the size of the defecting coalition of voters is bounded by $\delta$.

\section{Footnote 15 continued}

long as voters' strategies does not depend on the identities of the defecting politicians (e.g., sincere voting). In our model, all politicians in a party share equally in its power. Hence, if there does not exist a credible defection by a proper subcoalition of $\{1,2,3\}$, then there does not exist a credible defection by any single politician in $\{1,2,3,4,5,6\}$, which in turn implies that there does not exist a defection by any proper subset of $\{1,2,3,4,5,6\}$. Indeed, all our results on defection-proofness (Theorems 3, 5 and 6) remain unaltered.

16 Of course, defections by a coalition of voters with zero measure will not change the outcome.

17 The reason why credible defection by voters is well-defined is because given any voters' strategy profile $v_{s}^{0}$, it is impossible to find a nested sequence of sets of positive measures $A_{1} \supset A_{2} \supset A_{3} \ldots$ and corresponding sequence of profiles $\left(v_{s}^{1}, v_{s}^{2}, v_{s}^{3}, \ldots\right)$ such that $v_{s}^{k}$ is a defection from $v_{s}^{k-1}$ by $A_{k}$ for all $k \geq 1$. That is, there must exist a $K$ such that there is no defection from $v_{s}^{K}$ by any measurable $C \subset A_{K}$, and so $v_{S}^{K}$ is a credible defection from $v_{S}^{K-1}$ by $A_{K}$. To see this, suppose there exist such a nested sequence of voters and corresponding sequence of voters' strategy profiles. Then by the definition of defection by voters, all voters in $A_{k}$ strictly prefer the outcome (i.e., the combination of effective parties) in $v_{s}^{k}$ to the outcome in $v_{s}^{k^{\prime}}$ for all $k^{\prime}<k$. As $s$ is fixed, there is a finite number of possible outcomes, and hence, at some point along the sequence, say at $K+1$, we must obtain one of the outcomes that was observed before in the sequence. But that immediately implies that $v_{S}^{K+1}$ is not a defection from $v_{S}^{K}$ by $A_{K+1}$ because the voters in $A_{K+1}$ do not strictly prefer the outcome in $v_{S}^{K+1}$ to all the outcomes observed before. 
Fig. 1 The dotted lines demarcate arcs that define the distance between adjacent parties. The thick lines demarcate arcs that define each party's voter base or weight under sincere voting. The weight of a party under sincere voting is the average of its left and right distances

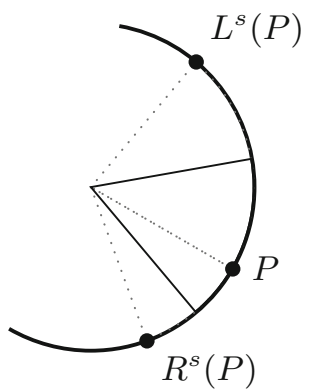

\section{Sincere voting}

In this section, we assume that each voter votes sincerely in Stage II for the party supporting the agenda nearest to her most-preferred agenda; in case there are two such parties, the indifferent voter votes for one of them using some tie-breaking rule. ${ }^{18}$ Let $s$ be the politicians' strategy profile in Stage I. We denote the voters' sincere strategy profile by $v_{s}^{*}$. For any $P \in \mathcal{P}(s)$, let $R^{S}(P)$ be the first party that is supporting an agenda in the clockwise direction starting at the agenda supported by $P$. Similarly, let $L^{S}(P)$ be the first party that is supporting an agenda in the counterclockwise direction starting at the agenda supported by $P$. Any two parties $P, P^{\prime} \in \mathcal{P}(s)$ are adjacent if $P^{\prime} \in\left\{L^{s}(P), R^{s}(P)\right\}$. We term the length of the arc between the agenda supported by $P$ and agenda supported by $L^{S}(P)$ as the left distance of party $P$ and denote it by $l^{s}(P)$. Similarly, the length of the arc between the agenda supported by $P$ and agenda supported by $R^{S}(P)$ will be called the right distance of party $P$ and denoted by $r^{s}(P)$. The distance between two parties is the minimum of the two.

As voters are assumed to vote sincerely, the weight of a party $P \in \mathcal{P}(s)$ is equal to half of the sum of its left and right distances: $w_{P}\left(s, v_{s}^{*}\right)=\frac{l^{s}(P)+r^{s}(P)}{2}$ (see Fig. 1).

\subsection{Nash equilibrium}

Since the voters vote sincerely in Stage II, we have to only analyze the strategic interaction among the politicians in Stage I. To this end, we first study the Nash equilibria of the Stage I game amongst the politicians under the assumption of sincere voting in Stage II.

Definition 5 (Nash equilibrium under sincere voting) The politicians' strategy profile $s$ is a Nash equilibrium under sincere voting if there do not exist $i \in I$ and $s_{i}^{\prime} \in A$ such that $u_{i}\left(\left(s_{i}^{\prime}, s_{-i}\right), v_{\left(s_{i}^{\prime}, s_{-i}\right)}^{*}\right)>u_{i}\left(\left(s_{i}, s_{-i}\right), v_{\left(s_{i}, s_{-i}\right)}^{*}\right)$.

\footnotetext{
${ }^{18}$ Since each voter has zero measure, all tie-breaking rules (e.g., vote for the nearest party in the clockwise direction, vote for the nearest party in the counterclockwise direction, or vote for both of these parties with equal probability) will result in the same outcome. Also, note that a voter can never be indifferent between more than two parties since the set of agendas is a circle.
} 
Thus, a Nash equilibrium under sincere voting is stable against unilateral deviations by a single politician.

The next theorem characterizes the set of Nash equilibria under sincere voting:

Theorem 1 The politicians strategy profile $s$ is a Nash equilibrium under sincere voting if and only if the numbers of politicians in any two parties in $\mathcal{P}(s)$ differ by at most 1, and exactly one of the following holds:

(i) $|\mathcal{P}(s)|=2$ and the distance between the parties is more than $\frac{1}{3}$.

(ii) $3 \leq|\mathcal{P}(s)| \leq \frac{|I|}{2}$ and all parties have equal weight.

(iii) $3 \leq|\mathcal{P}(s)| \leq 4,|\mathcal{P}(s)|>\frac{|I|}{2}$ and all parties are equidistant from each other.

(iv) $5 \leq|\mathcal{P}(s)| \leq 6,|\mathcal{P}(s)|>\frac{|I|}{2}$, all parties are equidistant from each other, and there does not exist any pair of singleton parties that are adjacent.

Thus, whether $s$ is a Nash equilibrium under sincere voting or not depends only on two factors: First, the respective distances between the agendas supported in $s$ which determine the weights of the parties — and second, the numbers of politicians in the parties formed in $s$. Hence, if $s$ is a Nash equilibrium under sincere voting, then the strategy profile $s^{\prime}$ obtained by either shifting the agendas supported by all politicians by a fixed constant or permuting the identities of the politicians will also be a Nash equilibrium under sincere voting. This is obviously because of the particular specification of the utilities of the politicians.

An important property of the Nash equilibrium under sincere voting is that all parties formed in equilibrium have equal weight (Lemma 7). This is because only those parties with the maximum weight obtain positive power. Hence, if a party has less than the maximum weight, then a politician belonging to that party obtains zero utility but could obtain positive utility by deviating to an agenda supported by some party (more precisely, any party with the highest weight in the hypothetical situation in which the set of politicians is $I \backslash\{i\}$, where $i$ is the deviating politician, and these politicians choose agendas according to the strategy profile $s_{-i}$ ).

As the weight of a party is the average of its left and right distances, the above mentioned property (Lemma 7) implies that the sums of the left and right distances of all parties formed in equilibrium are equal. Since the right (left) distance of party $P^{k}$ is trivially equal to the left (right) distance of $R^{s}\left(P^{k}\right)\left(L^{s}\left(P^{k}\right)\right)$, it follows that the left (right) distance of a party $P^{k}$ equals the right (left) distance of party $R^{s}\left(P^{k}\right)\left(L^{s}\left(P^{k}\right)\right)$. Therefore, if $\left\{P^{1}, \ldots, P^{n}\right\}$ is the set of parties that form in Nash equilibrium under sincere voting and, without loss of generality, $P^{k+1}=R^{s}\left(P^{k}\right)$ for all $k=1, \ldots, n-1$, then we obtain the following two sequences of equalities:

$$
\begin{aligned}
& l^{s}\left(P^{1}\right)=r^{s}\left(P^{2}\right)=l^{s}\left(P^{3}\right)=r^{s}\left(P^{4}\right)=\cdots \\
& l^{s}\left(P^{n}\right)=r^{s}\left(P^{1}\right)=l^{s}\left(P^{2}\right)=r^{s}\left(P^{3}\right)=\cdots
\end{aligned}
$$

In words, if we move along the circle in the clockwise direction, then every other arc defined by the set of agendas supported in equilibrium has the same length.

The property that all parties have equal weight in equilibrium generates two possible configurations of parties in equilibrium: 
Fig. 2 Odd number $(>1)$ of parties under sincere voting: (1) All parties have equal weight and are equidistant. (2) The locations of the parties are the vertices of a convex regular polygon

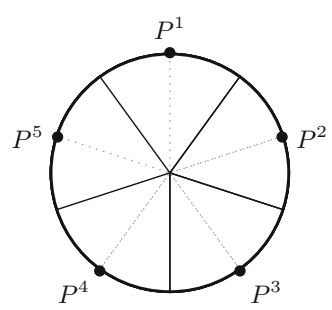

(1)

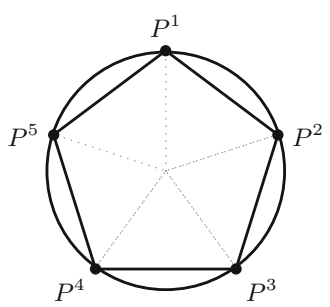

(2)

(i) An odd number of parties form in equilibrium. Then all parties must be equidistant from each other. To see this, suppose $n=5$, i.e., five parties $P^{1}, \ldots, P^{5}$ form in equilibrium (see Fig. 2(1)). Using (1), we obtain

$$
\begin{aligned}
l^{s}\left(P^{1}\right) & =r^{s}\left(P^{2}\right)=l^{s}\left(P^{3}\right)=r^{s}\left(P^{4}\right)=l^{s}\left(P^{5}\right)=r^{s}\left(P^{1}\right)=l^{s}\left(P^{2}\right) \\
& =r^{s}\left(P^{3}\right)=l^{s}\left(P^{4}\right)=r^{s}\left(P^{5}\right) .
\end{aligned}
$$

Since the parties are equidistant, the set of agendas supported in equilibrium $s$ can be graphically visualized as the vertices of a $n$-sided convex regular polygon (as shown in Fig. 2(2)).

(ii) An even number of parties form in equilibrium. First, consider the case when more than two parties form. Then both equidistant and non-equidistant configurations are possible. Figure 3 shows these configurations with six parties. In general, we can graphically visualize the set of agendas supported in equilibrium as follows. Since all parties have equal weight, we have

$$
l^{s}\left(P^{2}\right)+r^{s}\left(P^{2}\right)=l^{s}\left(P^{4}\right)+r^{s}\left(P^{4}\right)=l^{s}\left(P^{6}\right)+r^{s}\left(P^{6}\right)=\cdots
$$

But $l^{s}\left(P^{2}\right)+r^{s}\left(P^{2}\right)$ is the distance between the agendas supported by parties $P^{1}$ and $P^{3} ; l^{s}\left(P^{4}\right)+r^{s}\left(P^{4}\right)$ is the distance between the agendas supported by parties $P^{3}$ and $P^{5}$ and so on. Hence, all odd-numbered parties $\left(P^{1}, P^{3}, \ldots, P^{n-3}, P^{n-1}\right)$ are equidistant from each other, and thus the agendas supported by these parties are vertices of an $\frac{n}{2}$-sided convex regular polygon (as shown in Fig. 4(2)). Similarly, all even-numbered parties $\left(P^{2}, P^{4}, \ldots, P^{n-2}, P^{n}\right)$ are equidistant from each other and the agendas supported by these parties are also vertices of an $\frac{n}{2}$-sided convex regular polygon (as shown in Fig. 4(2)). If in addition, all parties are equidistant from each other, then the agendas supported by all parties are vertices of a $n$-sided convex regular polygon (as shown in Fig. 4(1)).

When only two parties form in equilibrium, each party has a weight of $\frac{1}{2}$. In this case, it must be that the distance between the two parties is greater than $\frac{1}{3}$. Otherwise, a single politician from the party having the larger number of politicians-who obtains a utility of at most $\frac{1}{4}$ as she shares power of $\frac{1}{2}$ with at least one other politician-can deviate to the agenda in the middle of the longer arc between the agendas supported by the two parties. The left and right distances 
Fig. 3 Even number ( $>2$ ) of parties under sincere voting: All parties have equal weight but both equidistant (shown in (1)) and non-equidistant (shown in (2)) configurations are possible. In (2), all even-numbered parties are equidistant from each other and all odd-numbered parties are equidistant from each other

Fig. 4 Even number ( $>2$ ) of parties under sincere voting: (1) When all parties are equidistant, their locations are the vertices of a convex regular polygon. (2) When parties are not equidistant, the locations of all even-numbered/odd-numbered parties are the vertices of a convex regular polygon

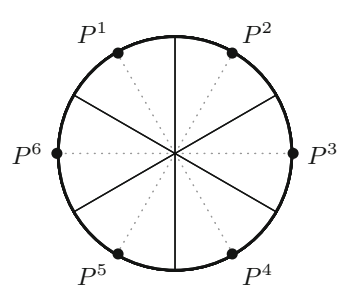

(1)

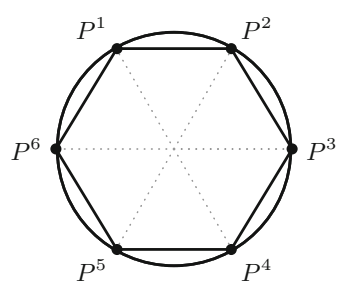

(1)

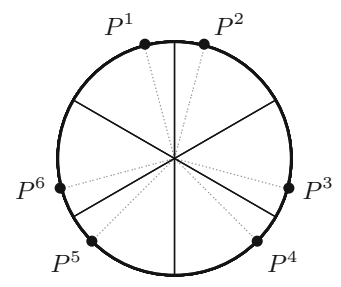

(2)

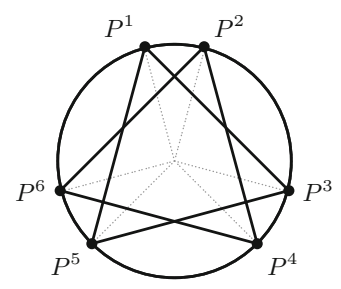

(2)

of this new singleton party will be both at least $\frac{1}{3}$, and hence it will have at least as much weight as the other two parties. Thus, the deviating politician will obtain a utility of at least $\frac{1}{3}$, which is a contradiction.

The utility of a politician is a function both of the weight of her party and the number of other politicians who belong to her party. Since all parties have the same weight in equilibrium, a politician in party $P$ obtains $\frac{1}{|P|}$ proportion of the weight. If there is another party $P^{\prime}$ such that $|P|>\left|P^{\prime}\right|+1$, then a politician from party $P$ could deviate to the agenda supported by $P^{\prime}$, increasing her utility to $\frac{1}{\left|P^{\prime}\right|+1}$ proportion of the weight. Therefore, the numbers of politicians in any two parties in $\mathcal{P}(s)$ differ by at most 1 in equilibrium.

It also follows from Theorem 1 that the number of parties formed in Nash equilibrium under sincere voting is bounded below by 2 and above by $\max \left\{\frac{|I|}{2}, 6\right\}$. Any strategy profile in which only a single party is formed is not an equilibrium since by deviating to any other agenda, any politician can form a singleton party with the weight of $\frac{1}{2}$, and hence increase her utility from at most $\frac{1}{3}$ - since $|I| \geq 3$ - to $\frac{1}{2}$. On the other hand, suppose the number of parties formed in equilibrium is greater than both $\frac{|I|}{2}$ and 6. Figure 5(1) shows such a strategy profile of the politicians when $|I|=17$ but nine parties form. Then at least one party, say $P^{2}$, is singleton and the utility of this politician is less than $\frac{1}{6}$ (see the figure). Since the numbers of politicians in any two parties cannot differ by more than 1 , both $P^{1}=L^{s}\left(P^{2}\right)$ and $P^{3}=R^{s}\left(P^{2}\right)$ have at most two members. Without loss of generality, let $r^{s}\left(P^{2}\right) \leq l^{s}\left(P^{2}\right)$. If the single politician in $P^{2}$ were to deviate to the agenda supported by $P^{3}$ (as shown in Fig. 5(2)), then the weight of party $P^{3} \cup P^{2}$ will increase by $\frac{l^{s}\left(P^{2}\right)}{2}$ and the weight of $P^{1}$ by $\frac{r^{s}\left(P^{2}\right)}{2}$, while the weights of all other parties will stay constant as the agendas supported by their respective adjacent parties stay fixed. Since we started with a situation of equal 


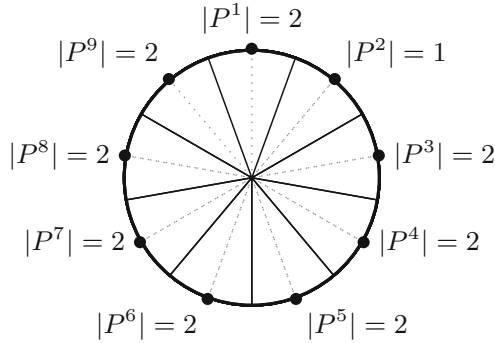

(1)

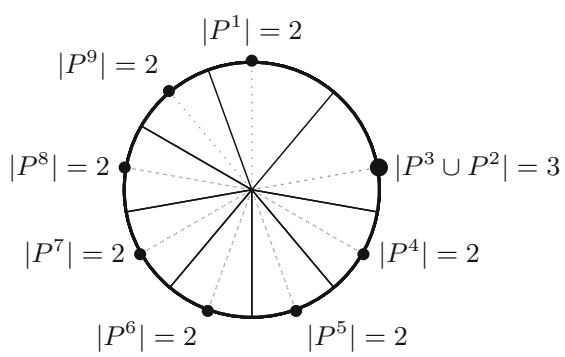

(2)

Fig. 5 Under sincere voting, the number of parties is bounded above by $\max \left\{\frac{|I|}{2}, 6\right\}$ : Assume $|I|=17$. (1) A strategy profile in which 9 parties form. (2) A unilateral deviation by the politician in $P^{2}$ that increases her utility

weights, the merged party $P^{3} \cup P^{2}$ will have the maximum weight, and hence, through this deviation, the politician will obtain a utility of at least $\frac{1}{6}$ as she shares the power of at least $\frac{1}{2}$ with at most two other members, which is a contradiction.

The following corollary immediately follows from Theorem 1 .

Corollary 2 For any $|I| \geq 3$, the set of Nash equilibria under sincere voting is nonempty.

Indeed, the model has multiple Nash equilibria under sincere voting with the number of political parties in equilibrium ranging from 2 to $\max \left\{\frac{|I|}{2}, 6\right\}$. Next, we refine our predictions using defection-proofness.

\subsection{Defection-proof Nash equilibrium}

A Nash equilibrium under sincere voting will not be stable if there exists a credible defection from it by coalitions of politicians. We therefore now restrict attention to defection-proof Nash equilibria.

Definition 6 (Defection-proof Nash equilibrium under sincere voting) The politicians' strategy profile $s$ is a defection-proof Nash equilibrium under sincere voting if given the sincere voting strategies in Stage II $\left(v_{\tilde{s}}^{*}\right)_{\tilde{s} \in A^{|I|}}$, there is no credible defection from $s$ by any coalition $J \subseteq I$.

Defection-proof Nash equilibria under sincere voting are stable against credible defections by any coalition of politicians. Clearly, the set of defection-proof Nash equilibria under sincere voting is a subset of the set of Nash equilibria under sincere voting.

The following theorem characterizes the set of defection-proof Nash equilibria under sincere voting.

Theorem 3 The politicians' strategy profile s is a defection-proof Nash equilibrium under sincere voting if and only if the numbers of politicians in any two parties in $\mathcal{P}(s)$ differ by at most 1 and exactly one of the following holds:

(i) $|\mathcal{P}(s)|=2$ and the distance between the parties is more than $\frac{1}{3}$. 


\section{(ii) $|\mathcal{P}(s)|=3$ and all parties are equidistant from each other.}

Thus, defection-proofness sharply refines the set of Nash equilibria under sincere voting: Only those Nash equilibria in which either two or three parties form are defection-proof. To see why Nash equilibria with at least four parties are not defectionproof, let's consider a Nash equilibrium $s$ in which $P^{1}, \ldots, P^{n}$ parties form, where $n \geq 4$, and all parties are equidistant, with the distance equal to $d$ (the proof takes care of all cases). Let $a$ be the agenda that is the midpoint of the agendas supported by $P^{2}$ and $P^{3}$ (as shown in Fig. 6(1)). Now, if a coalition consisting of all politicians in $P^{2}$ and $P^{3}$ were to deviate to supporting a, ceteris paribus, then $n-1$ parties, viz. $\left\{P^{1}, P^{2} \cup P^{3}, P^{4}, \ldots, P^{n}\right\}$, will be formed in the resulting profile $s^{\prime}$ (as shown in Fig. 6(2)). The weight of the party $P^{2} \cup P^{3}$ will be $\frac{3}{2} d$, while the weights of $P^{1}$ and $P^{4}$ will each be $\frac{5}{4} d$, and the weights of all other parties will remain unchanged. Since we started with a situation of equal weights, the merged party $P^{2} \cup P^{3}$ will be the unique party with the maximum weight, and hence each member of the deviating coalition will obtain a utility of $\frac{1}{\left|P^{2}\right|+\left|P^{3}\right|}$ compared to the utility of either $\frac{1}{n\left|P^{2}\right|}$ or $\frac{1}{n\left|P^{3}\right|}$ in profile $s$. Since $n \geq 4$ and the numbers of politicians in parties $P^{2}$ and $P^{3}$ do not differ from each other by more than $1-$ since $s$ is a Nash equilibrium -, we have $n\left|P^{2}\right| \geq 4\left|P^{2}\right|>2\left|P^{2}\right|+1 \geq\left|P^{2}\right|+\left|P^{3}\right|$, and similarly, $n\left|P^{3}\right|>\left|P^{2}\right|+\left|P^{3}\right|$. Thus, each member of the deviating coalition will be strictly better-off after the deviation, and hence we have obtained a defection from $s$ by coalition $P^{2} \cup P^{3}$. This defection is in fact credible. Consider any subcoalition $J^{\prime} \subset P^{2} \cup P^{3}$. If starting from $s^{\prime}$, all members of $J^{\prime}$ were to deviate to an agenda like $a^{\prime}$, which lies on the arc between the agendas supported by $P^{1}$ and $P^{4}$ that does not contain $a$ (see Fig. 6(2)), then at least as many agendas as in $s^{\prime}$ will be supported in the resulting profile $s^{\prime \prime}$. However, the weight of party $P^{2} \cup P^{3} \backslash J^{\prime}$ will not change while the weight of any other party will be at most $\frac{5}{4} d$. Hence, the subcoalition $J^{\prime}$ cannot improve its utility by this deviation. On the other hand, if starting from $s^{\prime}$, all members of $J^{\prime}$ were to deviate to an agenda like $a^{\prime \prime}$ or $a^{\prime \prime \prime}$, which lie between $a$ and the agenda supported by either $P^{1}$ or $P^{4}$ (see Fig. 6(2)), then the weight of party $J^{\prime}$ will be $\frac{3}{4} d$, which is less than the weight of $P^{2} \cup P^{3} \backslash J^{\prime}$. Thus, $J^{\prime}$ cannot improve its utility by such a deviation. Hence, we conclude that the initial defection from $s$ is a credible defection.

In contrast, all Nash equilibria under sincere voting in which either two or three parties form are defection-proof. Let's consider a Nash equilibrium $s$ as shown in Fig. 7(1) with three parties, $P^{1}, P^{2}$ and $P^{3}$ (the argument for two parties is similar). First, consider a defection in which all three parties merge, resulting in $s^{\prime}$ with a single agenda being supported. Since $s^{\prime}$ is not a Nash equilibrium under sincere voting, there exists a credible defection from $s^{\prime}$ by a single politician belonging to the initial defecting coalition. Thus, the initial defection cannot be credible. Second, consider a defection in which all politicians except some in say $P^{3}$ merge resulting in $s^{\prime}$ in which two agendas are supported (as shown in Fig. 7(2)). Thus, instead of $\frac{1}{3\left|P^{1}\right|}$, a defecting politician belonging to $P^{1}$ obtains a utility of at most $\frac{1}{2\left|P^{1}\right|+2\left|P^{2}\right|}$ after the defection. But $2\left|P^{1}\right|+2\left|P^{2}\right| \geq 2\left|P^{1}\right|+\left|P^{2}\right|+1 \geq 3\left|P^{1}\right|$, where the last inequality follows from the fact that the numbers of politicians in parties $P^{1}$ and $P^{2}$ do not differ from each other by more than 1 . Thus, any politician belonging to $P^{1}$ will not 


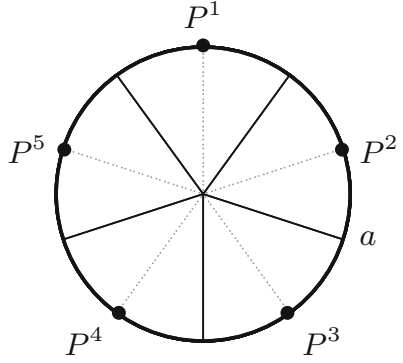

(1)

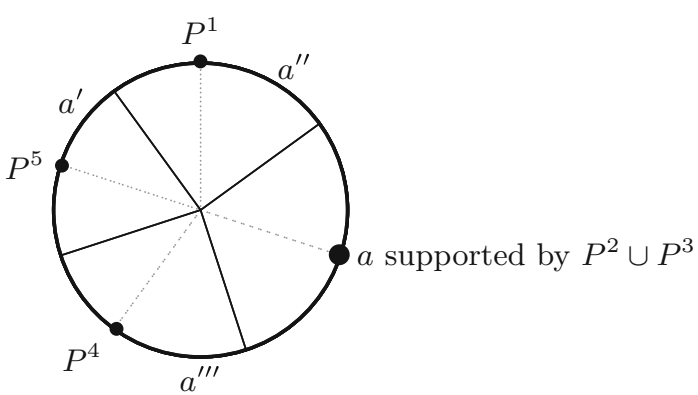

(2)

Fig. 6 Under sincere voting, Nash equilibria with more than 3 parties are not defection-proof: (1) A Nash equilibrium with 5 parties. (2) A credible defection by $P^{2} \cup P^{3}$

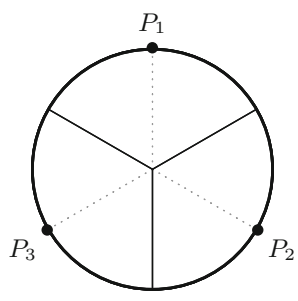

(1)

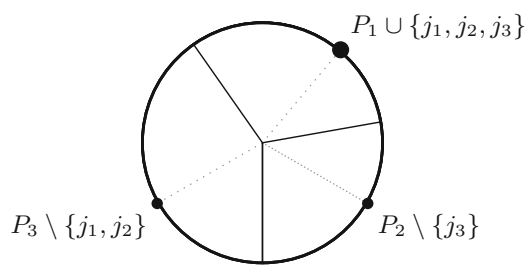

(3)

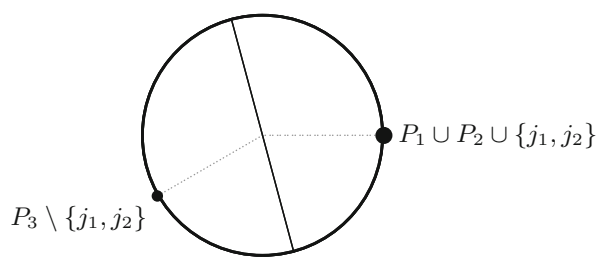

(2)

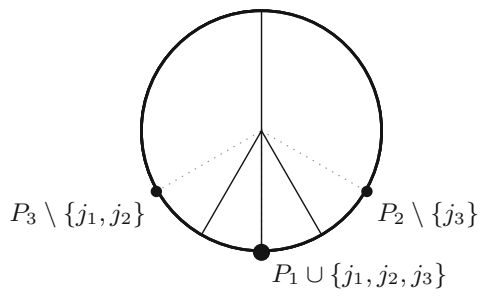

(4)

Fig. 7 Under sincere voting, Nash equilibria with 3 parties are defection-proof: (1) A Nash equilibrium with 3 parties. (2) There do not exist defections by politicians that result in only two supported agendas. (3) and (4) show that there do not exist defections by politicians that result in three supported agendas

improve her utility through this defection, a contradiction. Third, any defection that results in a $s^{\prime}$ in which three agendas are supported must be such that at least two agendas supported in $s$, say those of $P^{2}$ and $P^{3}$, are also supported in $s^{\prime}$. That is, some politicians belonging to $P^{2}$ and $P^{3}$ are not members of the defecting coalition. If the party formed supports an agenda which is different than the agenda supported by $P_{1}$ in $s$, then it has a weight of $\frac{1}{3}$ (Fig. 7(3)) or $\frac{1}{6}$ (Fig. 7(4)) depending on the arc on which the agenda is placed. In both cases, there is at least one party with a weight of strictly more than $\frac{1}{3}$. Therefore, the party formed has zero power and so the defection is not beneficial. If the party formed supports the agenda supported by $P_{1}$ in $s$, then all three agendas supported in $s$ are also supported in $s^{\prime}$. But such a defection even by 
a single politician is not beneficial since $s$ is a Nash equilibrium under sincere voting. Finally, any defection that results in a $s^{\prime}$ in which four agendas are supported must be such that all three agendas supported in $s$ are also supported in $s^{\prime}$ (note that there does not exist a defection that results in five or more supported agendas). But this cannot be beneficial for the same reasoning as above. Thus there is no credible defection from $s$ by any coalition of politicians.

As a corollary of Theorem 3, we easily obtain the following result:

Corollary 4 For any $|I| \geq 3$, the set of defection-proof Nash equilibria under sincere voting is nonempty.

\section{Strategic voting}

In this section, we analyze the case in which voters vote strategically. So now the two stages of our model define a two-stage game. We first look for the subgame-perfect Nash equilibria of this two-stage game. Subsequently, we refine our predictions using defection-proofness.

\subsection{Subgame-perfect Nash equilibrium}

To define subgame-perfect Nash equilibrium under strategic voting, we need to consider voters' strategies in all possible Stage II subgames. Note that there are $A^{|I|}$ possible subgames in Stage II, one corresponding to each strategy profile of the politicians.

Definition 7 (Subgame-perfect Nash equilibrium under strategic voting) The tuple of strategy profiles $\left(s,\left(v_{\tilde{s}}\right)_{\tilde{s} \in A^{|I|}}\right)$ is a subgame-perfect Nash equilibrium under strategic voting if for all $\tilde{s} \in A^{|I|}$, the voters' strategy profile $v_{\tilde{s}}$ is a Nash equilibrium in the Stage II subgame following $\tilde{s}$ in Stage I, and the politicians' strategy profile $s$ is a Nash equilibrium in the Stage I subgame given Stage II strategy profiles $\left(v_{\tilde{S}}\right)_{\tilde{s} \in A^{|I|}}$.

Since every profile of voters' strategies constitutes an equilibrium, for any choice of strategies by the politicians $s \in A^{|I|}$ there exists a subgame-perfect Nash equilibrium such that all parties in $\mathcal{P}(s)$ are effective in equilibrium. This implies that any number of effective parties between 1 and $|I|$ and their configuration over the circle are possible in subgame-perfect Nash equilibrium under strategic voting. In order to reduce the high multiplicity of equilibria, we will use the notion of $\delta$-defection-proof subgame-perfect Nash equilibrium which considers the possibility of coalitions of voters orchestrating defections.

\section{$4.2 \delta$-Defection-proof subgame-perfect Nash equilibrium}

A subgame-perfect Nash equilibrium under strategic voting will not be stable if there exists a credible defection by either a coalition of politicians or voters. We therefore now restrict our attention to defection-proof subgame-perfect Nash equilibria. Defection-proofness in our two-stage game requires that there is no credible defection by a coalition of players in either stage: 


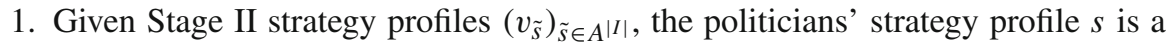
defection-proof Nash equilibrium in the Stage I subgame if there is no credible defection from $s$ by any coalition $J \subseteq I$.

2. The voter's strategy profile $v_{s}$ in the Stage II subgame following $s$ in Stage I is a $\delta$-defection-proof Nash equilibrium if there is no credible $\delta$-defection from $v_{s}$.

Definition 8 ( $\delta$-Defection-proof subgame-perfect Nash equilibrium under strategic voting) The tuple of strategy profiles $\left(s,\left(v_{\tilde{s}}\right)_{\tilde{s} \in A^{|I|}}\right)$ is a $\delta$-defection-proof subgameperfect Nash equilibrium under strategic voting if for all $\tilde{s} \in A^{|I|}$, the voters' strategy profile $v_{\tilde{s}}$ is a $\delta$-defection-proof Nash equilibrium in the Stage II subgame following $\tilde{s}$ in Stage I, and the politicians' strategy profile $s$ is a defection-proof Nash equilibrium in the Stage I subgame given Stage II strategy profiles $\left(v_{\tilde{S}}\right)_{\tilde{s} \in A^{|I|}}$.

It is clear that any $\delta$-defection-proof subgame-perfect Nash equilibrium under strategic voting is also a subgame-perfect Nash equilibrium under strategic voting.

Our next result shows that defection-proofness sharply refines the set of subgameperfect Nash equilibria under strategic voting: Irrespective of the value of $\delta$, any subgame-perfect Nash equilibrium under strategic voting with three or more effective parties in equilibrium is not $\delta$-defection-proof.

Theorem 5 Consider any $\delta \leq 1$. If $\left(s,\left(v_{\tilde{s}}\right)_{\tilde{s} \in A^{|I|}}\right)$ is a $\delta$-defection-proof subgameperfect Nash equilibrium under strategic voting, then there are at most two effective parties under $v_{s}$.

In the proof, we first argue that $\delta$-defection-proof Nash equilibrium requires that almost all voters vote sincerely in the Stage II subgames. If a positive proportion of the voters do not vote sincerely, then an $\epsilon$ proportion of them could switch their votes to their most-preferred party, making it the unique effective party. This defection is credible when $\epsilon$ is sufficiently small since then any further defection by a proper subcoalition of the voters will have no impact on the outcome. So suppose almost all voters are voting sincerely and there are three or more effective parties. Pick any two adjacent parties, $P^{1}$ and $P^{2}$, with $P^{2}$ in the clockwise direction of $P^{1}$. Due to the continuity of the voter's utility function, we can always find a positive proportion of the voters located between these two parties and closer to $P^{1}$ who prefer that $P^{2}$ wins for sure over a lottery in which a party that is even farther then $P^{2}$ could gain power. Thus, instead of voting sincerely, if an $\epsilon$ proportion of these voters defect and vote for $P^{2}$, then $P^{2}$ will become the unique effective party. For the same reason as mentioned above, this defection is credible when $\epsilon$ is sufficiently small.

We are unable to prove the existence of $\delta$-defection-proof subgame-perfect Nash equilibria under strategic voting when $\delta \geq 0.5$. However, it is more natural to consider the case when the feasible coalitions of voters are small in size. Specifically, we restrict attention to the case of $\delta<0.5$ (it is difficult to see how more than half the electorate can come together to identify and agree upon a credible defection). In that case, we have the following result:

Theorem 6 Let $\delta<0.5$.

(i) There exist $\delta$-defection-proof subgame-perfect Nash equilibria under strategic voting such that exactly one party is effective in equilibrium. 
(ii) There exist $\delta$-defection-proof subgame-perfect Nash equilibrium under strategic voting such that exactly two parties are effective in equilibrium. In such equilibria, we can obtain any distribution of politicians over the two effective parties as well as any distance between the pair of agendas supported by the two effective parties.

Thus, when $\delta$ is less than 0.5 , the set of $\delta$-defection-proof subgame-perfect Nash equilibria under strategic voting is nonempty and can generate both one effective party or two effective parties in equilibrium.

To construct the equilibrium with exactly one effective party, consider any politicians' strategy profile $s$ such that all politicians support the same agenda $a$. In order to ensure that no coalition of politicians have an incentive to defect from $s$, fix the voters' strategy profiles in the Stage II subgames as follows: If a coalition of politicians switch to supporting some agenda other than $a$, then the voters punish that coalition by continuing to vote for the remaining party which supports agenda $a$. This voters' strategy profile is a $\delta$-defection-proof Nash equilibrium in the Stage II subgame because, as $\delta<0.5$ and all voters vote for the same party, no coalition of voters with measure at most $\delta$ can change the outcome by defecting.

To construct the equilibrium with exactly two effective parties, consider any politicians' strategy profile $s$ such that a subset of the politicians support agenda $a$ while the rest support agenda $b$. In order to ensure that no coalition of politicians have an incentive to defect from $s$, fix the voters' strategy profiles in the Stage II subgames as follows: First, if a coalition of politicians in the party supporting one of the agendas, say $a$, switch to supporting the other agenda $b$, then the voters punish that coalition by voting only for the remaining party which supports $a$. Second, if a coalition of politicians form a third party by supporting an agenda other than $a$ or $b$, then again the voters punish that coalition by voting only for the party supporting $a$. Again, since $\delta<0.5$, these voters' strategy profiles are $\delta$-defection-proof subgame perfect Nash equilibria in the respective Stage II subgames. Notice that this argument does not rely on the distance between $a$ and $b$, and on the size of the two parties supporting these agendas. Thus, we conclude that the $\delta$-defection-proof subgame-perfect Nash equilibrium under strategic voting does not place any restriction on (a) the agendas supported by the two effective parties in equilibrium and (b) the distribution of politicians over the two effective parties in equilibrium.

\section{Relation to the linear model}

It is interesting to contrast the defection-proof equilibria that we obtain in our circular model to those we obtain when the space of agendas is the unit interval.

\section{Sincere voting}

When agendas are the unit interval, there are multiple Nash equilibria under sincere voting with one or more effective parties in equilibrium. For instance, the politicians' strategy profile in which all politicians choose the midpoint of the interval is obviously a Nash equilibrium under sincere voting. To obtain multiple effective parties in equi- 
librium, pick any integer $n$ such that $2 \leq n \leq \frac{|I|}{2}$. Consider a partition $\left\{P^{1}, \ldots, P^{n}\right\}$ of $I$ such that ||$P^{k}|-| P^{k^{\prime}}|| \leq 1$ for all $k, k^{\prime} \in\{1, \ldots, n\}$. Now define the politicians' strategy profile $s$ by placing all politicians in $P^{k}$ at $\frac{2 k-1}{2 n}$ distance from zero on the unit interval. Then $\mathcal{P}(s)=\left\{P^{1}, \ldots, P^{n}\right\}$ and, due to sincere voting, all parties have equal weight of $\frac{1}{n}$. Thus, all parties are effective. Since each party in $\mathcal{P}(s)$ has at least two politicians, a deviation by a single politician to an agenda that is not supported in $s$ will ensure that the deviating politician gets zero utility. Moreover, since ||$P^{k}|-| P^{k^{\prime}}|| \leq 1$ for all $k, k^{\prime}$, a deviation by a single politician to an agenda that is supported in $s$ will not increase her utility. Thus, $s$ is a Nash equilibrium under sincere voting.

If we now apply defection-proofness, then there is a unique defection-proof Nash equilibrium under sincere voting, which is the one in which all politicians choose the midpoint of the interval. The Nash equilibrium in which all politicians choose the midpoint is clearly defection-proof (and this is the only Nash equilibrium with one effective party). To prove that there are no other defection-proof Nash equilibria, consider any Nash equilibrium with multiple effective parties. Pick the left-most party, which must be effective in equilibrium. ${ }^{19}$ Now, if all the politicians in this left-most party move slightly to the right, then this party will increase its weight, and hence become the only effective party. Moreover, it is easy to show that there is no further defection by any subcoalition of these politicians. Hence, any Nash equilibrium under sincere voting with more than one party is not defection-proof.

\section{Strategic voting}

If we now allow for strategic voting by the voters located on the unit interval, then the results are almost the same as those for the case of the circular agenda space. For the same reasons as before, any choice of strategies by the politicians with any number of effective parties between 1 and $|I|$ can be supported in subgame-perfect Nash equilibrium. Theorem 5 also holds verbatim for this model (the proof is identical too). Thus, none of the subgame-perfect Nash equilibria with three or more effective parties are $\delta$-defection-proof for any $\delta$.

As in Theorem 6 , when $\delta<0.5$, we can show that there exist both types of $\delta$ defection-proof subgame-perfect Nash equilibria, viz., those in which only one party is effective and those in which two parties are effective. Among the $\delta$-defectionproof subgame-perfect Nash equilibria in which only one party is effective, the single effective party can support any agenda on the line (the proof is identical to that of Theorem 6(i)). However, unlike in the case of the circle, the distance between the agendas supported by the two effective parties in a $\delta$-defection-proof subgame-perfect Nash equilibrium cannot be arbitrary. This is because, when the voters' strategy profile in the Stage II subgame generates multiple effective parties, then such a strategy profile is a $\delta$-defection-proof Nash equilibrium in that subgame only if almost all voters vote

19 The reason for this is that no politician would like to stay in a party that is not effective in equilibrium. The precise argument is similar to the one in Lemma 7. 
sincerely over the effective parties. ${ }^{20}$ As a result, if we have two effective parties in equilibrium, and almost all voters must vote sincerely over these two parties, then the two parties must be equidistant from the midpoint.

\section{Summary}

Our aim in this paper was to study whether Duverger's Law can find game-theoretic foundations in a spatial model of party formation and electoral competition. As the standard model with a linear set of agendas has the tendency to drive politicians to centrism, we instead adopt the unit circle as the set of agendas. For both sincere voting and strategic voting, we find a large multiplicity of (subgame-perfect) Nash equilibria. We use the notion of defection-proof Nash equilibrium to refine our predictions and we find that defection-proofness refines in the direction predicted by Duverger's Law: Either two or three parties are effective under sincere voting while either one or two parties are effective under strategic voting. However, these results are only partially consistent with Duverger's Law since there exist defection-proof Nash equilibria with three parties under sincere voting and with one party under strategic voting.

Open Access This article is distributed under the terms of the Creative Commons Attribution 4.0 International License (http://creativecommons.org/licenses/by/4.0/), which permits unrestricted use, distribution, and reproduction in any medium, provided you give appropriate credit to the original author(s) and the source, provide a link to the Creative Commons license, and indicate if changes were made.

\section{Proofs: sincere voting}

Proof of Theorem 1 We prove the theorem through a series of lemmas.

Lemma 7 If $s$ is a Nash equilibrium under sincere voting with $|\mathcal{P}(s)| \geq 2$, then all parties in $\mathcal{P}(s)$ have equal weight.

Proof Suppose $s$ is a Nash equilibrium under sincere voting with $|\mathcal{P}(s)| \geq 2$ but there exists a $P \in \mathcal{P}(s)$ such that $w_{P}\left(s, v_{s}^{*}\right)<\max _{P^{\prime} \in \mathcal{P}(s)} w_{P^{\prime}}\left(s, v_{s}^{*}\right)$. Hence, $\rho_{P}\left(w\left(s, v_{s}^{*}\right)\right)=0$ and $u_{i}\left(s, v_{s}^{*}\right)=0$ for all $i \in P$. Pick any politician $i \in P$ and party $\hat{P} \in \arg \max _{P^{\prime} \in \mathcal{P}(s)} w_{P^{\prime}}\left(s, v_{s}^{*}\right)$. Consider the strategy profile $\left(s_{i}^{\prime}, s_{-i}\right)$ such that $s_{i}^{\prime}=\hat{a}$, where $\hat{a}$ is the agenda supported by $\hat{P}$ in $s$. Note that $\hat{P} \cup\{i\} \in \mathcal{P}\left(s_{i}^{\prime}, s_{-i}\right)$. If $\hat{P} \cup\{i\}=\arg \max _{P^{\prime} \in \mathcal{P}\left(s_{i}^{\prime}, s_{-i}\right)} w_{P^{\prime}}\left(\left(s_{i}^{\prime}, s_{-i}\right), v_{\left(s_{i}^{\prime}, s_{-i}\right)}^{*}\right)$, then $u_{i}\left(\left(s_{i}^{\prime}, s_{-i}\right), v_{\left(s_{i}^{\prime}, s_{-i}\right)}^{*}\right)$ $>0$, a contradiction.

If not, then pick any $\hat{P}^{\prime} \in \arg \max _{P^{\prime} \in \mathcal{P}\left(s_{i}^{\prime}, s_{-i}\right)} w_{P^{\prime}}\left(\left(s_{i}^{\prime}, s_{-i}\right), v_{\left(s_{i}^{\prime}, s_{-i}\right)}^{*}\right)$. Let $\hat{a}^{\prime}$ be the agenda supported by $\hat{P}^{\prime}$ in $\left(s_{i}^{\prime}, s_{-i}\right)$. Consider the strategy $\left(s_{i}^{\prime \prime}, s_{-i}\right)$ such that $s_{i}^{\prime \prime}=\hat{a}^{\prime}$. The sets of agendas supported by the parties are the same in $\left(s_{i}^{\prime}, s_{-i}\right)$ and

\footnotetext{
20 If this were not true, then a tiny proportion of voters could switch to their most-preferred effective party, making it the unique effective party, and thereby increasing their utility. Moreover, this defection is credible since the proportion of voters is tiny (a similar argument is made in Lemma 18).
} 
$\left(s_{i}^{\prime \prime}, s_{-i}\right)$. Hence, $\hat{P}^{\prime} \cup\{i\} \in \arg \max _{P^{\prime} \in \mathcal{P}\left(s_{i}^{\prime \prime}, s_{-i}\right)} w_{P^{\prime}}\left(\left(s_{i}^{\prime \prime}, s_{-i}\right), v_{\left(s_{i}^{\prime \prime}, s_{-i}\right)}^{*}\right)$. Therefore, $u_{i}\left(\left(s_{i}^{\prime \prime}, s_{-i}\right), v_{\left(s_{i}^{\prime \prime}, s_{-i}\right)}^{*}\right)>0$, a contradiction.

Lemma 8 If s is a Nash equilibrium under sincere voting with $|\mathcal{P}(s)| \geq 2$, then for any two adjacent parties $P$ and $P^{\prime}$ in $\mathcal{P}(s)$, we have $l^{s}(P)=r^{s}\left(P^{\prime}\right)$ and $r^{s}(P)=l^{s}\left(P^{\prime}\right)$. Furthermore, if $|\mathcal{P}(s)|$ is odd, then all parties are equidistant from each other.

Proof Let $P$ and $P^{\prime}$ be two adjacent parties in $\mathcal{P}(s)$. Without loss of generality, let $P^{\prime}=L^{s}(P)$. Hence, $l^{s}(P)=r^{s}\left(P^{\prime}\right)$. By Lemma $7, P$ and $P^{\prime}$ have equal weight. So $r^{s}(P)=l^{s}\left(P^{\prime}\right)$.

Let $P^{1}=P$ and $P^{k+1}=R^{s}\left(P^{k}\right)$ for $k=1, \ldots,|\mathcal{P}(s)|-1$. Note that $P^{|\mathcal{P}(s)|}=P^{\prime}$. If $|\mathcal{P}(s)|$ is odd, then we have $r^{s}\left(P^{1}\right)=l^{s}\left(P^{2}\right)=r^{s}\left(P^{3}\right)=\cdots=r^{s}\left(P^{|\mathcal{P}(s)|}\right)$, $r^{s}\left(P^{|\mathcal{P}(s)|}\right)=l^{s}\left(P^{1}\right)$ and $l^{s}\left(P^{1}\right)=r^{s}\left(P^{2}\right)=l^{s}\left(P^{3}\right)=\cdots=l^{s}\left(P^{|\mathcal{P}(s)|}\right)$. Therefore, all parties are equidistant from each other.

Lemma 9 If $s$ is a Nash equilibrium under sincere voting with $|\mathcal{P}(s)| \geq 2$, then we have $\max _{P, P^{\prime} \in \mathcal{P}(s)}|P|-\left|P^{\prime}\right| \leq 1$.

Proof Pick any $P, P^{\prime} \in \mathcal{P}(s)$. Without loss of generality, let $|P|>\left|P^{\prime}\right|+1$. Consider a politician $i \in P$. We have $u_{i}\left(s, v_{s}^{*}\right)=\frac{w_{P}\left(s, v_{s}^{*}\right)}{|P|}$. Let $s_{i}^{\prime}=a^{\prime}$, where $a^{\prime}$ is the agenda supported by party $P^{\prime}$ in $s$. Since the sets of agendas supported in $\left(s_{i}^{\prime}, s_{-i}\right)$ and $s$ are the same, all parties formed in $\left(s_{i}^{\prime}, s_{-i}\right)$ have equal weight ( $s$ is a Nash equilibrium and Lemma 7). Furthermore, the weight of party $P^{\prime} \cup\{i\}$ in the strategy profile $\left(s_{i}^{\prime}, s_{-i}\right)$ is equal to $w_{P^{\prime}}\left(s, v_{s}^{*}\right)$. Hence, $u_{i}\left(\left(s_{i}^{\prime}, s_{-i}\right), v_{\left(s_{i}^{\prime}, s_{-i}\right)}^{*}\right)=\frac{w_{P^{\prime}}\left(s, v_{s}^{*}\right)}{\left|P^{\prime}\right|+1}$. But $w_{P}\left(s, v_{s}^{*}\right)=w_{P^{\prime}}\left(s, v_{s}^{*}\right)$, by Lemma 7 . Therefore, $u_{i}\left(\left(s_{i}^{\prime}, s_{-i}\right), v_{\left(s_{i}^{\prime}, s_{-i}\right)}^{*}\right)>u_{i}\left(s, v_{s}^{*}\right)$, a contradiction.

Lemma 10 A strategy profile $s$ such that $|\mathcal{P}(s)|=2$ is a Nash equilibrium under sincere voting if and only if the distance between the parties is more than $\frac{1}{3}$ and $\max _{P, P^{\prime} \in \mathcal{P}(s)}|P|-\left|P^{\prime}\right| \leq 1$.

Proof Let $s$ be a Nash equilibrium under sincere voting such that $|\mathcal{P}(s)|=2$. Then it follows from Lemma 9 that $\max _{P, P^{\prime} \in \mathcal{P}(s)}|P|-\left|P^{\prime}\right| \leq 1$.

Let $\mathcal{P}(s)=\left\{P, P^{\prime}\right\}$. Since $|I| \geq 3$, at least one of the parties is not singleton. Without loss of generality, let $|P|>1$. Pick an $i \in P$. Since $w_{P}\left(s, v_{s}^{*}\right)=w_{P^{\prime}}\left(s, v_{s}^{*}\right)=$ $\frac{1}{2}$, we have $u_{i}\left(s, v_{s}^{*}\right) \leq \frac{1}{4}$.

Let $d=\min \left\{l^{s}(P), r^{s}(P)\right\}$. We call the arc between the agendas supported by parties $P$ and $P^{\prime}$ in $s$ with length $d$ as arc $d$, and the other arc as arc $1-d$ (in case $d=\frac{1}{2}$, then call any one of the two arcs defined by the agendas supported by $P$ and $P^{\prime}$ in $s$ as arc $d$ and the other as arc $1-d$ ).

Suppose $d \leq \frac{1}{3}$. Let politician $i$ deviate to $s_{i}^{\prime}$, which is the midpoint of arc $1-d$. In strategy profile $\left(s_{i}^{\prime}, s_{-i}\right)$, there are three parties $\{i\}, P \backslash\{i\}$ and $P^{\prime}$. Moreover, $w_{\{i\}}\left(\left(s_{i}^{\prime}, s_{-i}\right), v_{\left(s_{i}^{\prime}, s_{-i}\right)}^{*}\right)=\frac{1-d}{2} \geq \frac{1}{3}$ whereas $w_{P \backslash\{i\}}\left(\left(s_{i}^{\prime}, s_{-i}\right), v_{\left(s_{i}^{\prime}, s_{-i}\right)}^{*}\right)=$ $w_{P^{\prime}}\left(\left(s_{i}^{\prime}, s_{-i}\right), v_{\left(s_{i}^{\prime}, s_{-i}\right)}^{*}\right)=\frac{1+d}{4} \leq \frac{1}{3}$. Hence, $u_{i}\left(\left(s_{i}^{\prime}, s_{-i}\right), v_{\left(s_{i}^{\prime}, s_{-i}\right)}^{*}\right) \geq \frac{1}{3}$, a contradiction. 
To prove the other implication, suppose $s$ is a strategy profile with $\mathcal{P}(s)=\left\{P, P^{\prime}\right\}$, $d>\frac{1}{3}$ and $\max _{P, P^{\prime} \in \mathcal{P}(s)}|P|-\left|P^{\prime}\right| \leq 1$. Pick any $i \in P$. We have $u_{i}\left(s, v_{s}^{*}\right)=\frac{1}{2|P|}$. Consider any deviation $s_{i}^{\prime}$ by politician $i$. Now, two cases are possible:

(i) $|P|>1$ : Suppose $s_{i}^{\prime}$ is an unsupported agenda on $\operatorname{arc} d$. Then three parties $\{i\}, P \backslash\{i\}$ and $P^{\prime}$ form in $\left(s_{i}^{\prime}, s_{-i}\right)$. Moreover, $w_{\{i\}}\left(\left(s_{i}^{\prime}, s_{-i}\right), v_{\left(s_{i}^{\prime}, s_{-i}\right)}^{*}\right)=\frac{d}{2}$ whereas, since $d \leq \frac{1}{2}, w_{P \backslash\{i\}}\left(\left(s_{i}^{\prime}, s_{-i}\right), v_{\left(s_{i}^{\prime}, s_{-i}\right)}^{*}\right)>\frac{1}{2}-\frac{d}{2} \geq \frac{d}{2}$. Hence, $u_{i}\left(\left(s_{i}^{\prime}, s_{-i}\right), v_{\left(s_{i}^{\prime}, s_{-i}\right)}^{*}\right)=0$. So $i$ has no incentive to deviate from $s_{i}$ to $s_{i}^{\prime}$. Next, suppose $s_{i}^{\prime}$ is an unsupported agenda on arc $1-d$. Again, three parties $\{i\}, P \backslash\{i\}$ and $P^{\prime}$ form in $\left(s_{i}^{\prime}, s_{-i}\right)$. Moreover, $w_{\{i\}}\left(\left(s_{i}^{\prime}, s_{-i}\right), v_{\left(s_{i}^{\prime}, s_{-i}\right)}^{*}\right)=\frac{1-d}{2}$ but either $P^{\prime}$ or $P \backslash\{i\}$ has a weight of at least $\frac{1+d}{4}>\frac{1-d}{2}$ since $d>\frac{1}{3}$. Hence, $u_{i}\left(\left(s_{i}^{\prime}, s_{-i}\right), v_{\left(s_{i}^{\prime}, s_{-i}\right)}^{*}\right)=$ 0 and $i$ has no incentive to deviate from $s_{i}$ to $s_{i}^{\prime}$. Finally, if $s_{i}^{\prime}$ is the agenda supported by party $P^{\prime}$ in $s$, then $u_{i}\left(\left(s_{i}^{\prime}, s_{-i}\right), v_{\left(s_{i}^{\prime}, s_{-i}\right)}^{*}\right)=\frac{1}{2\left(\left|P^{\prime}\right|+1\right)} \leq \frac{1}{2|P|}$ since $|P|-\left|P^{\prime}\right| \leq 1$. So $i$ has no incentive to make this deviation.

(ii) $|P|=1$ : As long as $s_{i}^{\prime}$ is not the agenda supported by $P^{\prime}, u_{i}\left(\left(s_{i}^{\prime}, s_{-i}\right), v_{\left(s_{i}^{\prime}, s_{-i}\right)}^{*}\right)=$ $\frac{1}{2}$. If $s_{i}^{\prime}$ is the agenda supported by $P^{\prime}$, then $u_{i}\left(\left(s_{i}^{\prime}, s_{-i}\right), v_{\left(s_{i}^{\prime}, s_{-i}\right)}^{*}\right)=\frac{1}{\left|P^{\prime}\right|+1} \leq \frac{1}{3}$. So $i$ has no incentive to deviate.

A similar argument can be made for any politician in party $P^{\prime}$. Hence, $s$ is a Nash equilibrium under sincere voting.

Lemma 11 A strategy profile $s$ such that $|\mathcal{P}(s)| \geq 3$ and $|I| \geq 2|\mathcal{P}(s)|$ is a Nash equilibrium under sincere voting if and only if all parties in $\mathcal{P}(s)$ have equal weight and $\max _{P, P^{\prime} \in \mathcal{P}(s)}|P|-\left|P^{\prime}\right| \leq 1$.

Proof Suppose strategy profile $s$ is such that all parties have equal weight and $\max _{P, P^{\prime} \in \mathcal{P}(s)}|P|-\left|P^{\prime}\right| \leq 1$. Pick any $P \in \mathcal{P}(s)$ and $i \in P$. Since $w_{P}\left(s, v_{s}^{*}\right)=\frac{1}{|\mathcal{P}(s)|}$, we have $u_{i}\left(s, v_{s}^{*}\right)=\frac{1}{|\mathcal{P}(s)||P|}$. Furthermore, since $|I| \geq 2|\mathcal{P}(s)|$, we must have $\left|P^{\prime}\right| \geq 2$ for all $P^{\prime} \in \mathcal{P}(s)$. Consider any deviation $s_{i}^{\prime}$ by politician $i$. If $s_{i}^{\prime}$ is an agenda supported by some $P^{\prime} \in \mathcal{P}(s)$, then the sets of agendas supported by the parties are the same in $s$ and $\left(s_{i}^{\prime}, s_{-i}\right)$. Hence, all parties formed in $\left(s_{i}^{\prime}, s_{-i}\right)$ have equal weight and $w_{P^{\prime} \cup\{i\}}\left(\left(s_{i}^{\prime}, s_{-i}\right), v_{\left(s_{i}^{\prime}, s_{-i}\right)}^{*}\right)=w_{P^{\prime}}\left(s, v_{s}^{*}\right)$. Therefore, $u_{i}\left(\left(s_{i}^{\prime}, s_{-i}\right), v_{\left(s_{i}^{\prime}, s_{-i}\right)}^{*}\right)=$ $\frac{1}{|\mathcal{P}(s)|\left(\left|P^{\prime}\right|+1\right)} \leq \frac{1}{|\mathcal{P}(s)||P|}$ since $|P| \leq\left|P^{\prime}\right|+1$. If $s_{i}^{\prime}$ is an agenda that is not supported in strategy $s$, then there exists a $P^{\prime} \in \mathcal{P}(s)$ such that $s_{i}^{\prime}$ is between the agendas supported by $P^{\prime}$ and $L^{s}\left(P^{\prime}\right)$ in $s$. Hence, $w_{\{i\}}\left(\left(s_{i}^{\prime}, s_{-i}\right), v_{\left(s_{i}^{\prime}, s_{-i}\right)}^{*}\right)=\frac{l^{s}\left(P^{\prime}\right)}{2}$. But the weight of party $R^{\left(s_{i}^{\prime}, s_{i}\right)}\left(P^{\prime}\right)$ in $\left(s_{i}^{\prime}, s_{-i}\right)$ equals $\frac{l^{s}\left(P^{\prime}\right)+r^{s}\left(P^{\prime}\right)}{2}$ (using the fact that there are at least three parties in $s$ and all these parties have equal weight). Hence, $u_{i}\left(\left(s_{i}^{\prime}, s_{-i}\right), v_{\left(s_{i}^{\prime}, s_{-i}\right)}^{*}\right)=0$, and therefore there is no incentive for her to deviate. Lemmas 7 and 9 prove the other implication. 
Lemma 12 Under sincere voting, there does not exist a Nash equilibrium s such that either $(i)|\mathcal{P}(s)|=1$ or $($ ii $)|\mathcal{P}(s)|>6$ and $|I|<2|\mathcal{P}(s)|$.

Proof Suppose $s$ is such a Nash equilibrium. If $|\mathcal{P}(s)|=1$, then any politician $i$ can deviate to any $s_{i}^{\prime}$ and obtain $u_{i}\left(\left(s_{i}^{\prime}, s_{-i}\right), v_{\left(s_{i}^{\prime}, s_{-i}\right)}^{*}\right)=\frac{1}{2}>\frac{1}{|I|}=u_{i}\left(s, v_{s}^{*}\right)$. Next, if $|\mathcal{P}(s)|>6$ and $|I|<2|\mathcal{P}(s)|$, then there exists at least one party $P \in \mathcal{P}(s)$ such that $P=\{i\}$. It follows from Lemma 7 that $u_{i}\left(s, v_{s}^{*}\right)=\frac{1}{|\mathcal{P}(s)|}$. Let $P^{\prime}$ be the closest party adjacent to $P$ in $s$. We know that $\left|P^{\prime}\right| \in\{1,2\}$ (Lemma 9). If politician $i$ deviates to $s_{i}^{\prime}$, which is the agenda supported by $P^{\prime}$ in $s$, then there are at most two parties with the highest weight in $\left(s_{i}^{\prime}, s_{-i}\right)$ and $P^{\prime} \cup\{i\}$ is one of these two parties. Hence, $u_{i}\left(\left(s_{i}^{\prime}, s_{-i}\right), v_{\left(s_{i}^{\prime}, s_{-i}\right)}^{*}\right) \geq \frac{1}{2\left(\left|P^{\prime}\right|+1\right)} \geq \frac{1}{6}>\frac{1}{|\mathcal{P}(s)|}$, a contradiction.

Lemma 13 The politicians' strategy profile $s$ such that $5 \leq|\mathcal{P}(s)| \leq 6$ and $|I|<2|\mathcal{P}(s)|$ is a Nash equilibrium under sincere voting if and only if all parties are equidistant from each other, $\max _{P, P^{\prime} \in \mathcal{P}(s)}|P|-\left|P^{\prime}\right| \leq 1$, and there do not exist $P, P^{\prime} \in \mathcal{P}(s)$ such that $P$ and $P^{\prime}$ are adjacent, and $|P|=\left|P^{\prime}\right|=1$.

Proof Let $s$ be such a Nash equilibrium. First, suppose that the parties are not equidistant. It follows from Lemma 8 that $|\mathcal{P}(s)|=6$ and $l^{s}\left(P^{\prime \prime}\right) \neq r^{s}\left(P^{\prime \prime}\right)$ for all $P^{\prime \prime} \in \mathcal{P}(s)$. Since $|I|<2|\mathcal{P}(s)|$ there exists a party $P \in \mathcal{P}(s)$ such that $P=\{i\}$. Hence, $u_{i}\left(s, v_{s}^{*}\right)=\frac{1}{|\mathcal{P}(s)|}($ Lemma 7$)$. Let $P^{\prime}$ be the closest party adjacent to $P$ in $s$. We know that $\left|P^{\prime}\right| \in\{1,2\}$ (Lemma 9). If politician $i$ deviates to $s_{i}^{\prime}$, which is the agenda supported by $P^{\prime}$ in $s$, then the weight of party $P^{\prime} \cup\{i\}$ in $\left(s_{i}^{\prime}, s_{-i}\right)$ is strictly greater than any other party's weight, and hence $u_{i}\left(\left(s_{i}^{\prime}, s_{-i}\right), v_{\left(s_{i}^{\prime}, s_{-i}\right)}^{*}\right) \geq \frac{1}{3}>\frac{1}{6}$, a contradiction. Therefore, all parties in $s$ are equidistant from each other.

Next, suppose that there are two adjacent parties $P, P^{\prime} \in \mathcal{P}(s)$ such that $|P|=$ $\left|P^{\prime}\right|=1$. Let $P=\{i\}$. Then $u_{i}\left(s, v_{s}^{*}\right)=\frac{1}{|\mathcal{P}(s)|}$ (Lemma 7). If politician $i$ deviates to $s_{i}^{\prime}$, which is the agenda supported by $P^{\prime}$ in $s$, then there are exactly two parties in $\left(s_{i}^{\prime}, s_{-i}\right)$ with the highest weight and party $P^{\prime} \cup\{i\}$ in $\left(s_{i}^{\prime}, s_{-i}\right)$ is one of them. Hence, $u_{i}\left(\left(s_{i}^{\prime}, s_{-i}\right), v_{\left(s_{i}^{\prime}, s_{-i}\right)}^{*}\right)=\frac{1}{4}>\frac{1}{|\mathcal{P}(s)|}$, a contradiction.

Finally, we show the other implication. Let $s$ satisfy the conditions listed in the lemma. Pick any $P \in \mathcal{P}(s)$ and $i \in P$. Then $|P| \leq 2$ and $u_{i}\left(s, v_{s}^{*}\right)=\frac{1}{|\mathcal{P}(s)||P|}$. Consider any deviation $s_{i}^{\prime}$ by politician $i$.

(i) Suppose $|P|=2$ : If $s_{i}^{\prime}$ is an agenda supported by some $P^{\prime} \in \mathcal{P}(s)$, then the sets of agendas supported by the parties are the same in $s$ and $\left(s_{i}^{\prime}, s_{-i}\right)$. As a result, $w_{P^{\prime} \cup\{i\}}\left(\left(s_{i}^{\prime}, s_{-i}\right), v_{\left(s_{i}^{\prime}, s_{-i}\right)}^{*}\right)=w_{P^{\prime}}\left(s, v_{s}^{*}\right)$, and so $u_{i}\left(\left(s_{i}^{\prime}, s_{-i}\right), v_{\left(s_{i}^{\prime}, s_{-i}\right)}^{*}\right)=$ $\frac{1}{|\mathcal{P}(s)|\left(\left|P^{\prime}\right|+1\right)} \leq \frac{1}{|\mathcal{P}(s)||P|}$ since $|P| \leq\left|P^{\prime}\right|+1$. If $s_{i}^{\prime}$ is an agenda that is not supported by any party in strategy $s$, then there exists a $P^{\prime} \in \mathcal{P}(s)$ such that $s_{i}^{\prime}$ is between the agendas supported by $P^{\prime}$ and $L^{s}\left(P^{\prime}\right)$ in $s$. Hence, $w_{\{i\}}\left(\left(s_{i}^{\prime}, s_{-i}\right), v_{\left(s_{i}^{\prime}, s_{-i}\right)}^{*}\right)=\frac{l^{s}\left(P^{\prime}\right)}{2}$. But the weight of party $R^{\left(s_{i}^{\prime}, s_{i}\right)}\left(P^{\prime}\right)$ in $\left(s_{i}^{\prime}, s_{-i}\right)$ equals $\frac{l^{s}\left(P^{\prime}\right)+r^{s}\left(P^{\prime}\right)}{2}$ (using the fact that there are at least three parties in $s$ and all 
these parties have equal weight). Hence, $u_{i}\left(\left(s_{i}^{\prime}, s_{-i}\right), v_{\left(s_{i}^{\prime}, s_{-i}\right)}^{*}\right)=0$, and therefore there is no incentive for her to deviate.

(ii) Suppose $|P|=1$ : Let $\operatorname{arc} d^{\prime}$ be the arc between the agendas supported by $L^{S}(P)$ and $R^{s}(P)$ in $s$ that does not contain $s_{i}$. If $s_{i}^{\prime}$ is in $\operatorname{arc} d^{\prime}$ but $s_{i}^{\prime}$ is neither the agenda supported by $L^{s}(P)$ nor $R^{S}(P)$ in $s$, then parties $L^{S}(P)$ and $R^{S}(P)$ are also formed in strategy $\left(s_{i}^{\prime}, s_{-i}\right)$ and at least one of them obtains a higher weight than the party of politician $i$ in $\left(s_{i}^{\prime}, s_{-i}\right)$. Hence, $u_{i}\left(\left(s_{i}^{\prime}, s_{-i}\right), v_{\left(s_{i}^{\prime}, s_{-i}\right)}^{*}\right)=0$, and therefore there is no incentive to deviate. If $s_{i}^{\prime}$ is the agenda supported by $L^{s}(P)$ in $s$, then $L^{s}(P) \cup\{i\}$ and $R^{s}(P)$ form in strategy $\left(s_{i}^{\prime}, s_{-i}\right)$ and obtain the highest weight. Since $\left|L^{s}(P)\right|=2$, we have $u_{i}\left(\left(s_{i}^{\prime}, s_{-i}\right), v_{\left(s_{i}^{\prime}, s_{-i}\right)}^{*}\right)=\frac{1}{6}$. Therefore, there is no incentive to deviate. A similar argument works if $s_{i}^{\prime}$ is the agenda supported by $R^{s}(P)$ in $s$. In the remaining case, $u_{i}\left(\left(s_{i}^{\prime}, s_{-i}\right), v_{\left(s_{i}^{\prime}, s_{-i}\right)}^{*}\right)=0$ since both $L^{s}(P)$ and $R^{s}(P)$ are also formed in strategy $\left(s_{i}^{\prime}, s_{-i}\right)$ and at least one of them obtains a higher weight than the party of politician $i$ in $\left(s_{i}^{\prime}, s_{-i}\right)$. Hence, there is no incentive to deviate.

Therefore, $s$ is a Nash equilibrium under sincere voting.

Lemma 14 The politicians' strategy profile s such that $3 \leq|\mathcal{P}(s)| \leq 4$ and $|I|<2|\mathcal{P}(s)|$ is a Nash equilibrium under sincere voting if and only if all parties are equidistant from each other and $\max _{P, P^{\prime} \in \mathcal{P}(s)}|P|-\left|P^{\prime}\right| \leq 1$.

Proof The proof of this lemma is similar to the proof of Lemma 13.

The above lemmas together imply the characterization in the theorem.

Proof of Theorem 3 We prove the theorem through a series of lemmas.

Lemma 15 Let $s$ be such that $|\mathcal{P}(s)| \geq 4$. Then $s$ is not a defection-proof Nash equilibrium under sincere voting.

Proof Assume that $s$ is a defection-proof Nash equilibrium under sincere voting. Let $\mathcal{P}(s)=\left\{P^{1}, \ldots, P^{n}\right\}$ such that $n \geq 4$. Without loss of generality, let $P^{k+1}=R^{s}\left(P^{k}\right)$ for all $k=1, \ldots, n-1$ and $l^{s}\left(P^{\overline{3}}\right) \leq r^{s}\left(P^{3}\right)$. Since $s$ is a Nash equilibrium under sincere voting, all parties in $\mathcal{P}(s)$ have equal weight. Therefore, $u_{i}\left(s, v_{s}^{*}\right)=\frac{1}{|\mathcal{P}(s)|\left|P^{k}\right|}$ for all $i \in P^{k}$. Moreover, $\left|P^{2}\right|+\left|P^{3}\right| \leq 2\left|P^{k}\right|+1$ for $k=2,3$ (using Lemma 9).

Consider the arc between the agendas supported by $P^{2}$ and $P^{3}$ in $s$ corresponding to $l^{s}\left(P^{3}\right)$. Let $a$ be the midpoint of this arc. Consider the coalition $J=P^{2} \cup P^{3}$ and $s_{J}^{\prime}$ such that $s_{j}^{\prime}=a$ for all $j \in J$. Let $s^{\prime}=\left(s_{J}^{\prime}, s_{-J}\right)$. Now, $\mathcal{P}\left(s^{\prime}\right)=\left\{P^{1}, P^{2} \cup\right.$ $\left.P^{3}, P^{4}, \ldots, P^{n}\right\}$ and

$$
l^{s^{\prime}}\left(P^{2} \cup P^{3}\right)=l^{s}\left(P^{2}\right)+\frac{l^{s}\left(P^{3}\right)}{2}=r^{s}\left(P^{3}\right)+\frac{r^{s}\left(P^{2}\right)}{2}=r^{s^{\prime}}\left(P^{2} \cup P^{3}\right) .
$$

Thus, the weight of $P^{2} \cup P^{3}$ in $s^{\prime}$ equals $l^{s}\left(P^{2}\right)+\frac{l^{s}\left(P^{3}\right)}{2}$. Now, $r^{s^{\prime}}\left(P^{1}\right)=l^{s^{\prime}}\left(P^{2} \cup P^{3}\right)$ and $l^{s^{\prime}}\left(P^{1}\right)=l^{s}\left(P^{1}\right)=l^{s}\left(P^{3}\right) \leq r^{s}\left(P^{3}\right)=l^{s}\left(P^{2}\right)$. Similarly, $l^{s^{\prime}}\left(P^{4}\right)=r^{s^{\prime}}\left(P^{2} \cup\right.$ 
$\left.P^{3}\right)$ and $r^{s^{\prime}}\left(P^{4}\right) \leq r^{s}\left(P^{3}\right)$. Therefore, in $s^{\prime}, P^{2} \cup P^{3}$ has a greater weight than both $P^{1}$ and $P^{4}$. Clearly, $w_{P^{k}}\left(s^{\prime}, v_{s^{\prime}}^{*}\right)=w_{P^{k}}\left(s, v_{s}^{*}\right)$ for all $k>4$. Therefore, in $s^{\prime}, P^{2} \cup P^{3}$ is the unique party with the maximum weight. Hence, $u_{j}\left(s^{\prime}, v_{s^{\prime}}^{*}\right)=\frac{1}{\left|P^{2}\right|+\left|P^{3}\right|}$ for all $j \in J$.

Since $|\mathcal{P}(s)|\left|P^{k}\right| \geq 4\left|P^{k}\right|>2\left|P^{k}\right|+1 \geq\left|P^{2}\right|+\left|P^{3}\right|$ for $k=2,3, s_{J}^{\prime}$ is a defection from $s$ by $J$.

Consider any subcoalition $J^{\prime} \subset J$ and let $s_{J^{\prime}}^{\prime \prime}$ be such that $s_{j}^{\prime \prime}=a^{\prime} \neq a$ for all $j \in J^{\prime \prime}$. Let $s^{\prime \prime}=\left(s_{J^{\prime}}^{\prime \prime}, s_{-J^{\prime}}^{\prime}\right)$. If $a^{\prime}$ lies on the arc between the agendas supported by $P^{1}$ and $P^{4}$ in $s^{\prime}$ that does not contain $a$, then party $J \backslash J^{\prime}$ will be the unique party with the maximum weight in $s^{\prime \prime}$. Hence, the utility of each $j \in J^{\prime \prime}$ will be zero in $s^{\prime \prime}$. In all other cases, the new party $J^{\prime}$ will obtain a weight of $\frac{l^{s^{\prime}}\left(P^{2} \cup P^{3}\right)}{2}$, which is less than the weight obtained by at least either $P^{1}$ or $P^{4}$ in $s^{\prime \prime}$. Thus, the utility of each $j \in J^{\prime \prime}$ will again be zero in $s^{\prime \prime}$. So there does not exist any subcoalition $J^{\prime} \subset J$ with a defection from $s^{\prime}$. Therefore, $s_{J}^{\prime}$ is a credible defection from $s$ by $J$, a contradiction.

Lemma 16 Let $s$ be a Nash equilibrium under sincere voting such that $|\mathcal{P}(s)|=3$. Then $s$ is a defection-proof Nash equilibrium under sincere voting.

Proof Let $\mathcal{P}(s)=\left\{P^{1}, P^{2}, P^{3}\right\}, J$ a coalition of politicians, and $s_{J}^{\prime}$ a profile for this coalition such that $s_{j} \neq s_{j}^{\prime}=a$ for all $j \in J$. Suppose $s_{J}^{\prime}$ is a credible defection from $s$ by $J$. Consider the following cases:

(i) $P^{k} \backslash J \neq \varnothing$ for all $k \in\{1,2,3\}$. Pick any $j \in J$ and consider the strategy profile $\left(s_{j}^{\prime}, s_{-j}\right)$. Clearly the set of agendas supported in $\left(s_{J}^{\prime}, s_{-J}\right)$ is equal to the set of agendas supported in $\left(s_{j}^{\prime}, s_{-j}\right)$. Therefore, the weight of party supporting $a$ in $\left(s_{J}^{\prime}, s_{-J}\right)$ is equal to the weight of the party supporting $a$ in $\left(s_{j}^{\prime}, s_{-j}\right)$. But the latter party is singleton. Thus, $u_{j}\left(\left(s_{j}^{\prime}, s_{-j}\right), v_{\left(s_{j}^{\prime}, s_{-j}\right)}^{*}\right) \geq$ $u_{j}\left(\left(s_{J}^{\prime}, s_{-J}\right), v_{\left(s_{J}^{\prime}, s_{-J}\right)}^{*}\right)>u_{j}\left(s, v_{s}^{*}\right)$, a contradiction to the fact that $s$ is a Nash equilibrium.

(ii) $P^{1} \subseteq J$ and $P^{k} \backslash J \neq \emptyset$ for $k=2,3$. Then $a$ is not supported by $P^{1}$ in $s$. If $a$ is also not supported by $P^{2}$ or $P^{3}$ in $s$, then three parties form in $\left(s_{J}^{\prime}, s_{-J}\right)$ but the weight of the party supporting $a$ is less than the weight of at least one other party. Thus, $u_{j}\left(\left(s_{J}^{\prime}, s_{-J}\right), v_{\left(s_{J}^{\prime}, s_{-J}\right)}^{*}\right)=0$ for all $j \in J$, a contradiction. If $a$ is supported by, without loss of generality, $P^{2}$, then $P^{2} \cap J=\emptyset$. Now, two parties form in $\left(s_{J}^{\prime}, s_{-J}\right)$. Pick any $j \in P^{1}$. Then $u_{j}\left(\left(s_{J}^{\prime}, s_{-J}\right), v_{\left(s_{J}^{\prime}, s_{-J}\right)}^{*}\right) \leq$ $\frac{1}{2\left|P^{1}\right|+2\left|P^{2}\right|}$. On the other hand, $u_{j}\left(s, v_{s}^{*}\right)=\frac{1}{3\left|P^{1}\right|}$. However, $3\left|P^{1}\right| \leq 2\left|P^{1}\right|+$ $2\left|P^{2}\right|$ because $\left|P^{1}\right| \leq\left|P^{2}\right|+1 \leq 2\left|P^{2}\right|$. So $s_{J}^{\prime}$ cannot be a defection. Similarly, we can obtain contradictions when either:

(iii) $P^{2} \subseteq J$ and $P^{k} \backslash J \neq \emptyset$ for $k=1,3$, or

(iv) $P^{3} \subseteq J$ and $P^{k} \backslash J \neq \emptyset$ for $k=1,2$.

(v) $P^{1} \cup P^{2} \subseteq J$ and $P^{3} \backslash J \neq \varnothing$. Then $a$ is not supported by both $P^{1}$ and $P^{2}$ in $s$. If $a$ is also not supported by $P^{3}$ in $s$, then two parties form in $\left(s_{J}^{\prime}, s_{-J}\right)$. Pick any $j \in P^{1}$. Then $u_{j}\left(\left(s_{J}^{\prime}, s_{-J}\right), v_{\left(s_{J}^{\prime}, s_{-}\right)}^{*}\right) \leq \frac{1}{2\left|P^{1}\right|+2\left|P^{2}\right|}$. On the other hand, 
$u_{j}\left(s, v_{s}^{*}\right)=\frac{1}{3\left|P^{1}\right|}$. However, as above, $3\left|P^{1}\right| \leq 2\left|P^{1}\right|+2\left|P^{2}\right|$. So $s_{J}^{\prime}$ cannot be a defection, a contradiction. If $a$ is supported by $P^{3}$, then $P^{3} \cap J=\emptyset$. Now, a single party is formed in $\left(s_{J}^{\prime}, s_{-J}\right)$. However, since $\left(s_{J}^{\prime}, s_{-J}\right)$ is not a Nash equilibrium under sincere voting, there exists a credible defection by a single politician, without loss of generality by $j \in J$, from $\left(s_{J}^{\prime}, s_{-J}\right)$. Thus, $\left(s_{J}^{\prime}, s_{-J}\right)$ is not a credible defection from $s$ by $J$, a contradiction. We can similarly obtain contradictions when either:

(vi) $P^{1} \cup P^{3} \subseteq J$ and $P^{2} \backslash J \neq \emptyset$, or

(vii) $P^{2} \cup P^{3} \subseteq J$ and $P^{1} \backslash J \neq \emptyset$.

(viii) $P^{1} \cup P^{2} \cup P^{3}=J$. A single party is formed after the defection, and hence the resulting profile is not a Nash equilibrium under sincere voting. Thus, the initial defection is not credible, a contradiction.

Lemma 17 Let $s$ be a Nash equilibrium under sincere voting such that $|\mathcal{P}(s)|=2$. Then $s$ is a defection-proof Nash equilibrium under sincere voting.

Proof Let $\mathcal{P}(s)=\left\{P^{1}, P^{2}\right\}, J$ a coalition of politicians, and $s_{J}^{\prime}$ a profile for this coalition such that $s_{j} \neq s_{j}^{\prime}=a$ for all $j \in J$. Suppose $s_{J}^{\prime}$ is a credible defection from $s$ by $J$. Consider the following cases:

(i) $P^{k} \backslash J \neq \varnothing$ for all $k \in\{1,2\}$. Pick any $j \in J$ and consider the strategy profile $\left(s_{j}^{\prime}, s_{-j}\right)$. Clearly the set of agendas supported in $\left(s_{J}^{\prime}, s_{-J}\right)$ is equal to the set of agendas supported in $\left(s_{j}^{\prime}, s_{-j}\right)$. Therefore, the weight of party supporting $a$ in $\left(s_{J}^{\prime}, s_{-J}\right)$ is equal to the weight of the party supporting $a$ in $\left(s_{j}^{\prime}, s_{-j}\right)$. But the latter party is singleton. Thus, $u_{j}\left(\left(s_{j}^{\prime}, s_{-j}\right), v_{\left(s_{j}^{\prime}, s_{-j}\right)}^{*}\right) \geq u_{j}\left(\left(s_{J}^{\prime}, s_{-J}\right), v_{\left(s_{J}^{\prime}, s_{-J}\right)}^{*}\right)>$ $u_{j}\left(s, v_{s}^{*}\right)$, a contradiction to the fact that $s$ is a Nash equilibrium.

(ii) $P^{1} \subseteq J$ and $P^{2} \backslash J \neq \emptyset$. Then $a$ is not supported by $P^{1}$ in $s$. If $a$ is also not supported by $P^{2}$ in $s$, then two parties form in $\left(s_{J}^{\prime}, s_{-J}\right)$. The weight of the party supporting $a$ is equal to $\frac{1}{2}$. Thus, for any $j \in P^{1}$, we have $u_{j}\left(\left(s_{J}^{\prime}, s_{-J}\right), v_{\left(s_{J}^{\prime}, s_{-J}\right)}^{*}\right) \leq \frac{1}{2\left|P^{1}\right|}=u_{j}\left(s, v_{s}^{*}\right)$, a contradiction. If $a$ is supported by $P^{2}$, then $P^{2} \cap J=\emptyset$. Now, a single party is formed in $\left(s_{J}^{\prime}, s_{-J}\right)$. However, since $\left(s_{J}^{\prime}, s_{-J}\right)$ is not a Nash equilibrium, $\left(s_{J}^{\prime}, s_{-J}\right)$ is not a credible defection from $s$ by $J$, a contradiction. We can similarly obtain a contradiction when:

(iii) $P^{2} \subseteq J$ and $P^{1} \backslash J \neq \emptyset$.

(iv) $P^{1} \cup P^{2}=J$. A single party is formed after the defection, and hence the resulting profile is not a Nash equilibrium. Thus, the initial defection is not credible, a contradiction.

These lemmas together imply the characterization in the theorem.

\section{Proofs: strategic voting}

Proof of Theorem 5: We first prove the following lemma: 
Lemma 18 Consider any $\delta \leq 1$. Under strategic voting, if $v_{s}$ is a $\delta$-defection-proof Nash equilibrium in the subgame following $s$ in Stage I, then there are at most two effective parties under $v_{s}$.

Proof Consider the subgame following the strategy profile $s$ of politicians. Suppose there are three or more effective parties under $v_{s}$. Let $P_{1}$ be one such effective party. Now move in clockwise direction from $P_{1}$ and let $P_{2}$ be the first party in that direction that is also effective under $v_{s}$. Let $a$ be the midpoint between the agendas supported by parties $P_{1}$ and $P_{2}$.

First, suppose there exists a positive measure of voters between the agenda supported by $P_{1}$ and $a$ that do not vote for $P_{1}$ under $v_{s}$. Pick a subset $B$ of these voters with measure $\epsilon$ such that $0<\epsilon \leq \delta$. Let $v_{s}^{\prime}$ be the strategy profile that results when all voters in $B$ switch their votes to $P_{1}$ ceteris paribus. Under $v_{s}^{\prime}$, only party $P_{1}$ is effective. All voters in $B$ are strictly better-off under $v_{s}^{\prime}$ because among all parties that are effective under $v_{s}$, voters in $B$ are closest to $P_{1}$.

Suppose there exists a subset of voters $C \subset B$ such that $C$ has positive but smaller measure than $B$ and there is a defection from $v_{s}^{\prime}$ by $C$. Call this defection $v_{s}^{\prime \prime}$. Since all voters in $C$ strictly prefer the agenda supported by $P_{1}$ to any of the agendas supported by other parties that are effective under $v_{s}$, it must be that voters in $C$ switch their votes to a party say $P_{3}$ that is not effective under $v_{s}$ but is effective under $v_{s}^{\prime \prime}$. However, if $\epsilon$ is sufficiently small, then it is impossible for party $P_{3}$ to be effective under $v_{s}^{\prime \prime}$. To see this, let $w_{P_{1}}\left(s, v_{s}^{\prime \prime}\right)$ and $w_{P_{3}}\left(s, v_{s}^{\prime \prime}\right)$ be the weights of, respectively, parties $P_{1}$ and $P_{3}$ under $v_{s}^{\prime \prime}$. Similarly, let $w_{P_{1}}\left(s, v_{s}\right)$ and $w_{P_{3}}\left(s, v_{s}\right)$ be the weights of, respectively, parties $P_{1}$ and $P_{3}$ under $v_{s}$. Then

$$
w_{P_{1}}\left(s, v_{s}^{\prime \prime}\right) \geq w_{P_{1}}\left(s, v_{s}\right)>w_{P_{3}}\left(s, v_{s}\right) \quad \text { and } \quad w_{P_{3}}\left(s, v_{s}^{\prime \prime}\right) \leq w_{P_{3}}\left(s, v_{s}\right)+\epsilon .
$$

Thus, if $\epsilon$ is small enough, we must have $w_{P_{1}}\left(s, v_{s}^{\prime \prime}\right)>w_{P_{3}}\left(s, v_{s}^{\prime \prime}\right)$.

Second, suppose almost all voters between the agenda supported by $P_{1}$ and $a$ vote for $P_{1}$ under $v_{s}$. The voter located at $a$ is indifferent between the agendas supported by $P_{1}$ and $P_{2}$ but strictly prefers both these agendas to those supported by other effective parties under $v_{s}$. Therefore, this voter will strictly prefer the agenda supported by $P_{2}$ to the lottery over agendas generated under $v_{s}$. As a result, a positive proportion of the voters located beside $a$ in the counterclockwise direction will also prefer the agenda supported by $P_{2}$ to the lottery over agendas generated under $v_{s}$. Pick a subset $B$ of these voters with measure $\epsilon$ such that $0<\epsilon \leq \delta$. Let $v_{s}^{\prime}$ be the strategy profile that results when all voters in $B$ switch their votes to $P_{2}$ ceteris paribus. Under $v_{s}^{\prime}$, only party $P_{2}$ is effective. Moreover, all voters in $B$ are strictly better-off under $v_{s}^{\prime}$.

Suppose there exists a subset of voters $C \subset B$ such that $C$ has positive but smaller measure than $B$ and there is a defection from $v_{s}^{\prime}$ by $C$. Call this defection $v_{s}^{\prime \prime}$. If all voters in $C$ switch their votes to a party say $P_{3}$ that is not effective under $v_{s}$ but is effective under $v_{s}^{\prime \prime}$, then like above, we can argue that if $\epsilon$ is sufficiently small, then it is impossible for party $P_{3}$ to be effective under $v_{s}^{\prime \prime}$. Thus, if $v_{s}^{\prime \prime}$ is a defection from $v_{s}^{\prime}$ by $C$, then it must be that all voters in $C$ switch their votes from $P_{2}$ to a party that is effective under $v_{s}$. But all these voters strictly prefer the agenda supported by $P_{2}$ to the agendas supported by all parties that are effective under $v_{s}$ except party $P_{1}$. Hence, it 
must be that all voters in $C$ switch their votes to party $P_{1}$. But in $v_{s}$, all voters in $C$ are voting for party $P_{1}$ and $w_{P_{1}}\left(s, v_{s}\right)=w_{P_{2}}\left(s, v_{s}\right)$. Since $C$ has a smaller measure than $B$, we must have $w_{P_{1}}\left(s, v_{s}^{\prime \prime}\right)<w_{P_{2}}\left(s, v_{s}^{\prime \prime}\right)$. So party $P_{1}$ cannot be effective under $v_{s}^{\prime \prime}$.

Thus, we have argued that there exists credible $\delta$-defection from $v_{s}$. Hence, $v_{s}$ is not a $\delta$-defection-proof Nash equilibrium in the subgame following $s$ in Stage I.

The theorem follows from the above lemma since $\delta$-defection-proof subgame-perfect Nash equilibrium requires the voters' strategy profiles to be $\delta$-defection-proof Nash equilibria in the respective Stage II subgames.

Proof of Theorem 6 First, we show that there exists a $\delta$-defection-proof subgameperfect Nash equilibrium $\left(s,\left(v_{\tilde{s}}\right)_{\tilde{s} \in A^{|I|}}\right)$ such that exactly one party is effective under $v_{s}$. Consider any Stage I strategy profile $s$ such that all politician choose the same agenda $a$, and hence $\mathcal{P}(s)=\{P\}$. For all $\tilde{s}$, define $v_{\tilde{s}}$ as follows:

- $\tilde{s}$ is such that $|\mathcal{P}(\tilde{s})|=1$. Then $v_{\tilde{s}}$ is such that all voters vote for the single party in $\mathcal{P}(\tilde{s})$. Of course, then $v_{\tilde{s}}$ is the unique $\delta$-defection-proof Nash equilibrium in this subgame.

- $\tilde{s}$ is such that $\mathcal{P}(\tilde{s})$ is not singleton and there exists a party in $P^{\prime} \in \mathcal{P}(\tilde{s})$ that supports $a$. Then $v_{\tilde{s}}$ is such that all voters vote for party $P^{\prime}$. Since $\delta<0.5$, it is impossible for a coalition of voters of measure at most $\delta$ to switch their votes an make another party in $\mathcal{P}\left(s^{\prime}\right)$ effective. Hence, there is no $\delta$-defection from $v_{\tilde{s}}$. So $v_{\tilde{s}}$ is a $\delta$-defection-proof Nash equilibrium in the subgame following $\tilde{s}$.

- $\tilde{s}$ is such that $\mathcal{P}(\tilde{s})$ is not singleton and there does not exist a party in $\mathcal{P}(\tilde{s})$ that supports $a$. Then let $v_{\tilde{s}}$ be such that all voters vote for a single party in $\mathcal{P}(\tilde{s})-$ the single party can be chosen arbitrarily. Again, since $\delta<0.5, v_{\tilde{s}}$ is a $\delta$-defectionproof Nash equilibrium in the subgame following $\tilde{s}$.

We now argue that $s$ is a defection-proof Nash equilibrium in the Stage I subgame given the Stage II strategy profiles $\left(v_{\tilde{s}}\right)_{\tilde{s} \in A^{|I|}}$. Any defection by a coalition $J$ of politicians either leads to a strategy profile $s^{\prime}$ such that $\left|\mathcal{P}\left(s^{\prime}\right)\right|=1$ or $\left|\mathcal{P}\left(s^{\prime}\right)\right|=2$. When $\left|\mathcal{P}\left(s^{\prime}\right)\right|=$ 1 , all politicians' utilities remain the same both before and after the deviation. Hence, there is no such defection. When $\left|\mathcal{P}\left(s^{\prime}\right)\right|=2$, then there exists a party $P^{\prime} \in \mathcal{P}\left(s^{\prime}\right)$ that supports $a$. Hence, according to $v_{s^{\prime}}$ defined above, the deviating politicians get zero utility under $s^{\prime}$. Therefore, there is no such defection.

The above arguments imply that $\left(s,\left(v_{\tilde{s}}\right)_{\left.\tilde{s} \in A^{|I|}\right)}\right.$ is a $\delta$-defection-proof subgameperfect Nash equilibrium under strategic voting.

Second, we show that there exists a $\delta$-defection-proof subgame-perfect Nash equilibrium $\left(\hat{s},\left(\hat{v}_{\tilde{s}}\right)_{\tilde{s} \in A^{|I|}}\right)$ such that exactly two parties are effective under $\hat{v}_{\hat{s}}$. Consider any Stage I strategy profile $\hat{s}$ such that some politicians choose some agenda $a$ while the rest choose another agenda $b \neq a$. Then $\mathcal{P}(\hat{s})=\left\{P^{1}, P^{2}\right\}$, where $P^{1}$ is the set of politicians choosing $a$ and $P^{2}$ is choosing $b$ (notice that we make no assumption regarding the size of $P_{1}$ and $P_{2}$ ). Let $\hat{v}_{\hat{s}}$ be such that almost all voters vote sincerely over the two parties in $P^{1}$ and $P^{2}$. For all $\tilde{s} \neq \hat{s}$, define $\hat{v}_{\tilde{s}}$ as follows:

- $\tilde{s}$ is such that $|\mathcal{P}(\tilde{s})|=1$. Then $\hat{v}_{\tilde{s}}$ is such that all voters vote for the single party in $\mathcal{P}(\tilde{s})$. Of course, then $\hat{v}_{\tilde{s}}$ is the unique $\delta$-defection-proof Nash equilibrium in this subgame. 
- $\tilde{s}$ is such that $|\mathcal{P}(\tilde{s})|=2$ and $a$ is supported by party $P^{a}$ while $b$ is supported by party $P^{b}$ in $\mathcal{P}(\tilde{s})$ such that $P^{1} \subset P^{a}$. Then $P^{b} \subset P^{2}$. Then let $\hat{v}_{\tilde{s}}$ be such that all voters vote for $P^{b}$. Since $\delta<0.5$, it is impossible for a coalition of voters of measure at most $\delta$ to switch their votes and make a party other than $P^{b}$ effective. Hence, there is no $\delta$-defection from $\hat{v}_{\tilde{s}}$. So $\hat{v}_{\tilde{s}}$ is a $\delta$-defection-proof Nash equilibrium in the subgame following $\tilde{s}$.

- $\tilde{s}$ is such that $|\mathcal{P}(\tilde{s})|=2$ and $a$ is supported by party $P^{a}$ while $b$ is supported by party $P^{b}$ in $\mathcal{P}(\tilde{s})$ such that $P^{2} \subset P^{b}$. Then $P^{a} \subset P^{1}$. Then let $\hat{v}_{\tilde{s}}$ be such that all voters vote for $P^{a}$. Since $\delta<0.5$, it is impossible for a coalition of voters of measure at most $\delta$ to switch their votes and make a party other than $P^{a}$ effective. Hence, there is no $\delta$-defection from $\hat{v}_{\tilde{s}}$. So $\hat{v}_{\tilde{S}}$ is a $\delta$-defection-proof Nash equilibrium in the subgame following $\tilde{s}$.

- $\tilde{s}$ is such that $|\mathcal{P}(\tilde{s})|=2$ and $\tilde{s}$ does not fall into the previous two cases. Then let $\hat{v}_{\tilde{s}}$ be such that almost all voters vote sincerely over the two parties in $\mathcal{P}(\tilde{s})$. If there is a $\delta$-defection from $\hat{v}_{\tilde{s}}$, then it must be that a measurable subset of voters $B$ switch their votes from one party in $\mathcal{P}(\tilde{s})$ to the other. But as almost all voters vote sincerely in $\hat{v}_{\tilde{s}}$, such a switch in votes by the voters in $B$ will ensure that only that party which almost all voters in $B$ find less desirable is effective. Hence, there is no $\delta$-defection from $\hat{v}_{\tilde{s}}$. So $\hat{v}_{\tilde{s}}$ is a $\delta$-defection-proof Nash equilibrium in the subgame following $\tilde{s}$.

- $\tilde{s}$ is such that $|\mathcal{P}(\tilde{s})| \geq 3$ and both $a$ and $b$ are supported by some parties in $\mathcal{P}(\tilde{s})$. Suppose $a$ is supported by party $P^{\prime} \in \mathcal{P}(\tilde{s})$. Then let $\hat{v}_{\tilde{s}}$ be such that all voters vote for $P^{\prime}$. Since $\delta<0.5$, it is impossible for a coalition of voters of measure at most $\delta$ to switch their votes and make a party other than $P^{\prime}$ effective. Hence, there is no $\delta$-defection from $\hat{v}_{\tilde{s}}$. So $\hat{v}_{\tilde{s}}$ is a $\delta$-defection-proof Nash equilibrium in the subgame following $\tilde{s}$.

- $\tilde{s}$ is such that $|\mathcal{P}(\tilde{s})| \geq 3$ and either $a$ or $b$ is not supported by a party in $\mathcal{P}(\tilde{s})$. Then let $\hat{v}_{\tilde{s}}$ be such that all voters vote for any single party in $\mathcal{P}(\tilde{s})$ - the single party can be chosen arbitrarily. Again, since $\delta<0.5, \hat{v}_{\tilde{s}}$ is a $\delta$-defection-proof Nash equilibrium in the subgame following $\tilde{s}$.

We now argue that $\hat{s}$ is a defection-proof Nash equilibrium in the Stage I subgame given the Stage II strategy profiles $\left(\hat{v}_{\tilde{s}}\right)_{\tilde{s} \in A^{|I|}}$. Any defection by a coalition $J$ of politicians leads to a strategy profile $s^{\prime}$ such that one of the following is true:

1. $\left|\mathcal{P}\left(s^{\prime}\right)\right|=1$. Then after the deviation by coalition $J$, all politicians get a utility of $\frac{1}{|I|}$. If $|J|=1$, then the deviation cannot be improving for the single deviating politician as her utility goes down from $\frac{1}{2}$ to $\frac{1}{|I|}$. Hence, there is no such defection from $\hat{s}$. If $|J| \geq 2$, then the defection by $J$ is not credible since a single politician from $J$ can further deviate to a new agenda and, according to $\left(\hat{v}_{\tilde{s}}\right)_{\tilde{s} \in A^{|I|}}$, increase her utility from $\frac{1}{|I|}$ to $\frac{1}{2}$.

2. $\left|\mathcal{P}\left(s^{\prime}\right)\right|=2$. Suppose both $a$ and $b$ are supported by parties in $\mathcal{P}\left(s^{\prime}\right)$. Then the defection by $J$ involves a switch by these politicians from one party in $\mathcal{P}(s)$ to the other. Without loss of generality, suppose politicians in $J$ switch from supporting agenda $a$ to agenda $b$. Then, according to $\hat{v}_{s^{\prime}}$ defined above for this case, only that party in $\mathcal{P}\left(s^{\prime}\right)$ which supports agenda $a$ will be effective. Hence, none of the 
politicians in $J$ will increase her utility after this deviation. So there is no such defection from $\hat{s}$.

Suppose only one of $a$ or $b$ is supported by a party in $\mathcal{P}\left(s^{\prime}\right)$. Without loss of generality, suppose only $a$ is supported by a party in $\mathcal{P}\left(s^{\prime}\right)$. Then the deviation by $J$ involves all politicians in $P^{2}$ switching to another agenda. But, according to $\hat{v}_{S^{\prime}}$ defined above for this case, both parties in $\mathcal{P}\left(s^{\prime}\right)$ will be effective. Hence, none of the politicians in $P^{2}$ will increase her utility after this deviation. Therefore, there is no such defection from $\hat{s}$.

3. $\left|\mathcal{P}\left(s^{\prime}\right)\right|=3$. In this case, both $a$ and $b$ are supported by parties in $\mathcal{P}\left(s^{\prime}\right)$. Then the deviation by $J$ involves some politicians switching to an agenda other than $a$ or $b$. But then, according to $\hat{v}_{s^{\prime}}$ defined above for this case, the deviating politicians will get zero utility after the deviation. Therefore, there is no such defection from $\hat{s}$.

The above arguments imply that $\left(\hat{s},\left(\hat{v}_{\tilde{s}}\right)_{\tilde{s} \in A^{|I|}}\right)$ is a $\delta$-defection-proof subgame-perfect Nash equilibrium.

\section{References}

Aumann R (1959) Acceptable points in general cooperative $n$-person games. In: Tucker A, Luce R (eds) Contributions to the theory of games IV. Princeton University Press, Princeton, pp 287-324

Bernheim B, Peleg B, Whinston M (1987) Coalition-proof Nash equilibria I: concepts. J Econ Theory 42(1):1-12

Besley T, Coate S (1997) An economic model of representative democracy. Q J Econ 112(1):85-114

Brandt M, Evans A, Crawford J (2015) The unthinking or confident extremist? Political extremists are more likely than moderates to reject experimenter-generated anchors. Psychol Sci 26(2):189-202

Cox G (1987) Electoral equilibrium under alternative voting institutions. Am J Polit Sci 31(1):82-108

Downs A (1957a) An economic theory of democracy. Harper and Row, New York

Downs A (1957b) An economic theory of political action in a democracy. J Polit Econ 65(2):135-150

Duverger M (1954) Political parties. Wiley, New York

Eguia J (2013) The origin of parties: theory, and evidence from the United States Congress 1789-1797. Econ Polit 25(3):313-334

Faye J-P (1973) Langages totalitaires: critique de la raison/l'économie narrative. Hermann, Paris

Feddersen T (1992) A voting model implying Duverger's Law and positive turnout. Am J Polit Sci 36(4):938-962

Fey M (1997) Stability and coordination in Duverger's Law: a formal model of preelection polls and strategic voting. Am Polit Sci Rev 91(1):135-147

Fey M (2007) Duverger's Law without strategic voting. In: Working paper

Gupta B, Lai F-C, Pal D, Sarkar J, Yu C-M (2004) Where to locate in a circular city? Int J Ind Organ 22(6):759-782

Hotelling H (1929) Stability in competition. Econ J 39(153):41-57

Jackson M, Moselle B (2002) Coalition and party formation in a legislative voting game. J Econ Theory 103(1):49-87

Kaminski M (2006) A general equilibrium model of multi-party competition. Soc Choice Welf 26(2):333361

Levy G (2004) A model of political parties. J Econ Theory 115(2):250-277

Lijphart A (1990) The political consequences of electoral laws, 1945-85. Am Polit Sci Rev 84(2):481-496

McClosky H, Chong D (1985) Similarities and differences between left-wing and right-wing radicals. Br J Polit Sci 15(3):329-363

Morelli M (2004) Party formation and policy outcomes under different electoral systems. Rev Econ Stud 71(3):829-853

Osborne M, Slivinski A (1996) A model of political competition with citizen-candidates. Q J Econ 111(1):65-96 
Osborne M, Tourky R (2008) Party formation in single-issue politics. J Eur Econ Assoc 6(5):974-1005

Palfrey T (1989) A mathematical proof of Duverger's Law. In: Ordeshook P (ed) Models of strategic choice in politics. University of Michigan Press, Ann Arbor, pp 69-91

Peeters R, Saran R, Yüksel A (2010) Strategic party formation on a circle. Meteor Research Memorandum $10 / 045$

Persson T, Tabellini G (2000) Political economics: explaining economic policy. MIT Press, Cambridge

Rae D (1971) The political consequences of electoral laws, 2nd edn. Yale University Press, New Haven

Riker W (1982) The two-party system and Duverger's Law: an essay on the history of political science. Am Polit Sci Rev 76(4):753-766

Rivière A (1998) Citizen candidacy, party formation, and Duverger's Law. Université Libre de Bruxelles, Mimeo

Salop S (1979) Monopolistic competition with outside goods. Bell J Econ 10(1):141-156

Snyder J Jr, Ting M (2002) An informational rationale for political parties. Am J Polit Sci 46(1):90-110

Taagepera R, Shugart M (1989) Seats and votes: the effects and determinants of electoral systems. Yale University Press, New Haven 